\title{
Labor Market Polarization and International Macroeconomic Dynamics
}

\author{
Federico S. Mandelman
}

\section{Working Paper 2013-17 \\ December 2013}

\begin{abstract}
During the last thirty years, labor markets in advanced economies were characterized by their remarkable polarization. As job opportunities in middle-skill occupations disappeared, employment opportunities concentrated in the highest- and lowest-wage occupations. I develop a two-country stochastic growth model that incorporates trade in tasks, rather than in goods, and reveal that this setup can replicate the observed polarization in the United States. This polarization was not a steady process: the relative employment share of each skill group fluctuated significantly over short-to-medium horizons. I show that the domestic and international aggregate shocks estimated within this framework can rationalize such employment dynamics while providing a good fit to the macroeconomic data. The model is estimated with employment data for different skills groups and trade-weighted macroeconomic indicators.
\end{abstract}

JEL classification: F16, F41

Key words: labor market polarization, international business cycles, heterogeneous agents, stochastic growth, two-country models

$\overline{\text { Fernando Rios-Avila and Jing Yu provided superb research assistance. The author gratefully acknowledges David Dorn for very }}$ helpful interactions concerning the data analysis. He also thanks Andrei Zlate, Pedro Silos, and conference and seminar participants at the Society for Economic Dynamics, Midwest Macro, Econometric Society, the Federal Reserve Bank of Philadelphia, University of Georgia, Riksbank, ICEF, Universidad Torcuato Di Tella, Universidad de San Andres, Universidad Catolica, the Universidad de Montevideo, and the central banks of Argentina, Chile, and Uruguay for helpful comments. Part of this work was completed while the author was visiting Universidad Torcuato Di Tella. The views expressed here are the author's and not necessarily those of the Federal Reserve Bank of Atlanta or the Federal Reserve System. Any remaining errors are the author's responsibility.

Please address questions regarding content to Federico S. Mandelman, Federal Reserve Bank of Atlanta, Research Department, 1000 Peachtree Street, N.E., Atlanta, GA 30309-4470, 404-498-8785, federico.mandelman@atl.frb.org.

Federal Reserve Bank of Atlanta working papers, including revised versions, are available on the Atlanta Fed's website at frbatlanta.org. Click "Publications" and then "Working Papers." Use the WebScriber Service (at frbatlanta.org) to receive e-mail notifications about new papers. 


\section{Introduction}

Concern is growing about the disappearance of jobs available for middle-skill workers. Fig. 1(a) shows the change in the share of U.S. total employment in 318 occupations since 1980 (with skill rank approximated by the average wage in each occupation). The figure demonstrates that middle-skill occupations witnessed a decrease in their share of total employment as employment shifted towards both the bottom and high end of skill distributions. ${ }^{1}$ Other advanced economies display similar trends. ${ }^{2}$

International trade appears to be a decisive factor in this shift. In particular, tasks typically held by middle-skill workers are increasingly offshored overseas (See Ottaviano et al, 2013). In addition, Firpo et al (2011) disaggregate the task content of each job and quantify the role that technology and offshoring play in labor market polarization, finding that the last factor became predominant in the $1990 \mathrm{~s}^{3}{ }^{3}$ To account for this finding, in this paper, I introduce a tractable model where international trade delivers this polarization. The model indicates the presence of trade in tasks rather than in goods, as originally coined by Grossman and Rossi-Hansberg $(2008,2012)$. Namely, as revolutionary advances in transportation and communication take place, international trade increasingly involves small amounts of value added in different locations rather than as a standard exchange of finished goods. Firms can deliver instructions instantaneously and move components of unfinished goods quickly and cheaply. This facility allows firms to incorporate labor inputs in the production process that are located in different countries.

For instance, as trade links deepen, U.S. workers can specialize in design and marketing of a new high-tech computer device while countries with a different local expertise (Indian programmers to debug software, Korean technicians to provide microchips, and Chinese workers to assemble the final product) can accomplish other tasks. In the U.S., those high-skilled individuals working on design and marketing will benefit from trade as the new high-tech device will be sold globally, whereas the relatively less skilled workers will be displaced by foreigners unless offshoring costs fail to justify sending the work overseas.

\footnotetext{
${ }^{1}$ See Acemoglu and Autor (2011) for data and references.

${ }^{2}$ See, for instance, Goss and Manning (2007).

${ }^{3}$ See also Goos et al (2011) and references therein.
} 
Trade in tasks can explain why those with high skills stand a better chance in the global marketplace than the middle-skilled, but this observation alone is unable to account for the polarization that also benefits those at the very bottom of the skill distribution chain. This paper argues that low-skill workers select into occupations that are "protected" from the offshoring wave. As shown in Autor and Dorn (2012), this skill group specializes in manual tasks that require little (if any) training. It includes janitors, gardeners, home health aides, and child care workers. In general, these tasks are only valuable for the consumer if they are executed in the place where the final good or service is delivered. For instance, a bartendering service is useful only in a restaurant while a construction laborer must work in the physical place where the structure is being built. Offshoring is no threat for these tasks, and as incomes of high-skill individuals increase so does the demand for these type of services. This occurrence ultimately benefits the employment prospects of the low-skilled. Adding to this evidence, Fig. 1(b) shows that occupations providing non-tradable services explain practically all of the employment gains for the low-skilled in the past three decades. ${ }^{4}$

However, one puzzling aspect of the labor market polarization remains: it did not occur at a steady rate. As explained in detail by Acemoglu and Autor (2011), some striking and pronounced 'twists' occurred in the distribution of employment across occupations over the period under consideration. Fig. 2 shows the same data as Fig. 1 but depicted separately over each of the past three decades. Evidence indicates that during the 1980s (1979-1989) employment growth was widespread but quantitatively monotone in occupational skill level. Consequently, in this figure, occupations at the bottom of the skill distribution saw declines in their share of total employment, those at the middle roughly maintained their position, and the high-skilled increased their share. In the 1990s, this monotonous relationship gave way to a distinctive polarization pattern with a hollowing out of the middle. Finally, during the last decade (19992007), employment growth heavily concentrated at the bottom. That is, in the years preceding the crisis, low-skilled jobs expanded robustly while other skill groups stalled.

\footnotetext{
${ }^{4}$ This figure considers a simple counterfactual in which employment for these occupations is held constant at its original 1980 level. See more details in the statistical appendix.
} 
A model that is either static or limited to comparisons of long-run positions or growth dynamics has difficulty in capturing these 'twists.' Therefore, the stochastic growth model in this paper incorporates trade in tasks within an international macroeconomic framework, which also is able to analyze short- to medium-run business cycle dynamics. I use full information methods to estimate the transitory and permanent shocks within this configuration. The estimation includes high frequency U.S. employment data for different skill groups as well as domestic and trade-weighted foreign macroeconomic aggregates. In the baseline specification, I consider a set of standard shocks that affect technology (total factor productivity), trade (offshoring) costs, and consumption demand (inter-temporal rate of substitution).

I next quantify the contribution that these estimated shocks play in the evolution of U.S. employment over the past thirty years. Results indicate that during the 1980s, labor-augmenting technological innovations benefitting the skilled workers played a predominant role in driving the aggregate dynamics. These shocks closely resemble a typical "Harrod-Balassa-Samuelson" scenario such that productivity growth in the non-tradable low-skilled service sector is subdued. Consistent with the evidence for the 1980s, the substitution effect following these shocks dictates employment gains that are monotonic in skill. In the 1990s, offshoring became a critical factor (see Firpo et al, 2011). Coincidentally, the quantitative analysis shows that shocks resulting in a decrease in offshoring costs played a decisive role in this decade, in turn leading to offshoring of middle-skill tasks and the polarization of the labor market. In the early 2000s, the so-called "global imbalances" or "savings glut" hypothesis dominated much of the economic debate. In fact, a sizable increase in the global supply of savings translated into foreign capital inflows toward the U.S. aimed at financing a domestic consumption boom. Within the boundaries of my model, such a scenario resembles a shock to inter-temporal consumption preference: the foreign economy postpones consumption, accumulates assets, and runs a protracted trade surplus to finance current consumption in the domestic economy. In such an event, the home economy leans toward the production of non-tradable low-skill tasks to the detriment of tradables tasks (which are supplied in "excess" by the rest of the world). In my model, these type of demand shocks consistently played a major role in the years preceding the 
crisis. The associated employment gains for the low-skilled also resemble the historical recollection for this past decade. ${ }^{5}$

Finally, I show that this framework also can deliver predictions for macroeconomic aggregates that are consonant with some well-established international business cycle facts. In particular, the model delivers more accurate business cycle synchronization (output and factor co-movement) and more realistic cyclical dynamics for the real exchange rate.

In this paper, Section 2 characterizes the modelling approach and discusses the related literature. Section 3 introduces the model, and Section 4 presents the data and model estimation. Section 5 follows with an exploration the effect of the estimated shocks and the role that they play in assessing the historical evidence. Section 6 discusses the model fit and its business cycle properties of the model, with Section 7 concluding the paper.

\section{Related literature and modelling approach}

The analytical framework consists of a two-country stochastic growth model of trade and macroeconomics. Households can freely allocate unskilled labor in the non-tradable service sector or invest in training, thus creating a diversity of occupations that fulfill different tasks. Job creation and hiring depend on macroeconomic and trade policy conditions and expectations of forward-looking agents. The training (or job creation) cost involves an irreversible investment, creating an initial uncertainty concerning the future productivity of the job post. Upon the job is created productivity is revealed. Firms can hire workers in the global market to accomplish a certain number of tasks, but they must pay an "offshoring" costs, including transportation as well as those associated with remote monitoring and adaptability of offered foreign skills to the local practice. Given these costs, multinational firms will demand only the most productive workers from each country, which benefits workers with high ability worldwide. The evidence supports this claim as inequality deepens when countries (at any stage of development) lower

\footnotetext{
${ }^{5}$ As shown in Kehoe et al (2013), increasing foreign borrowing is associated with labor shifting away from the goods sector toward services and construction.
} 
barriers to trade. ${ }^{6}$

Standard trade models have difficulty in accounting for the protracted job losses in the middle of the skill distribution set. Ricardian comparative advantage predicts that some industries shrink as a country specializes in the most efficient locale. However, Jaimovich and Siu (2012) show that the polarization is not a sectoral phenomenon because middle-skill job losses are recorded across all industries. In addition, Acemoglu and Autor (2011) show that these employment losses are consistently documented across all countries in their sample. My model consistently delivers widespread middle-skill employment losses that are neither sector nor country specific.

Some notable contributions in trade theory address the polarization of the labor market. Helpman et al (2010 a,b) incorporate Diamond-Mortensen-Pissarides (DMP) labor frictions and heterogeneity among workers' abilities. This idiosyncratic ability is not ex-ante observable, and firms are forced to pre-screen the potential employees. When the economy opens up, only the firms that more thoroughly screen workers survive. The enhanced screening by most productive firms does not affect workers with very low abilities (who, in any event, were never hired) or those with high skills (who actually are selected). But instead those in the middle experience the most negative effects. Grossman and Rossi-Hansberg (2008, 2012) formalize the trade-in-tasks hypothesis in the presence of offshoring. ${ }^{7}$ In turn, Costinot and Vogel (2010) show that polarization also is possible when they consider a Roy-like task assignment trade model. Blanchard and Willmann (2013) extend the Grossman and Rossi-Hansberg setup to consider a situation in which middle-skill tasks are outsourced. In this context, more capable agents react by investing more in human capital while others with moderate-to-low ability optimally invest less. All these contributions in trade theory are developed within a static framework with only qualitative implications. By contrast, the quantitative general equilibrium framework that I use in this paper is dynamic and stochastic. This framework allows me to apply the model directly to the data and study short- to medium-run dynamics

\footnotetext{
${ }^{6}$ See for instance Goldberg and Pavcnik (2007) and Han et al (2012) for a discussion. Instead, the traditional HecksherOhlin/Stolper-Samuelson trade paradigm contradicts this fact. Due to specialization, this theory predicts that the skill premium must fall in countries with relatively abundant unskilled labor once they open to trade. See Burstein and Vogel ( 2012) for a discussion.

${ }^{7}$ Grossman and Rossi-Hanberg (2012) emphasize that the presence of external economies of scale: a firm that executes a task in a specific location may develop a local expertise in that task, inducing others to execute the same task in that place.
} 
of employment and other trade and financial aggregates in response to different shocks. In other words, one fundamental goal for this paper is to bridge the existing gap between trade-in-tasks theory and international macroeconomics while addressing polarization of the labor market. Another feature of my approach is to highlight the role that the low-skill non-tradable sector plays, which previously was not considered in this context.

Another branch of the theory focuses on closed-economy models based on routine-biased technological change to explain a polarization. Preeminent examples include Acemoglu and Autor (2011) and Jaimovich and Siu (2012). This modelling strategy captures the documented fact that middle-skill workers typically are trained to accomplish "routine" tasks. These tasks can be summarized in a well-defined set of instructions and procedures, which increasingly are being replaced by technology that is embedded in equipment (e.g. bank tellers by ATMs). Although this type of technical change plays an important role, it is hard to reconcile notable "twists" in the employment share of each skill group over the last three decades as previously discussed solely through a technological change that simply erases middle-skill tasks steadily over time. Nonetheless, in an attempt to address this important issue, I introduce capital into my model and consider the effect of investment-specific technological (IST) innovations that lower the relative price of equipment. The polarization is enhanced in this scenario: Firms substitute away from labor towards capital, allowing multinational firms to become even more selective when hiring workers in the global marketplace (magnifying the displacement of middle-skill workers). In turn, cheaper capital goods enhance aggregate productivity and the demand for non-tradables. Since the low-skill service sector is labor intensive, these IST innovations do not directly affect it. Consequently, low-skill employment increases in tandem with high-skill income share.

In my approach, job creation resembles the firm entry with idiosyncratic productivity in Melitz (2003). While only the most productive firms trade internationally in the Melitz model, my model demonstrates that high ability workers are the ones with the skills that multinational firms in the global marketplace demand. Indeed, my model is more closely associated with Ghironi and Melitz (2005) that appends the 
Melitz setup with a dynamic stochastic international business cycle framework. Two extensions of this last model also are related to my paper: Cacciatore (2013) adds DMP labor market frictions, and Zlate (2012) incorporates offshoring through vertical foreign direct investment. None of these models, however, allow for skill heterogeneity, occupational choice, and trade in tasks.

Other notable empirical papers that have documented the polarization phenomena include Acemoglu (1999), Autor et al (2006), Goos and Maning (2007), and Goos et al (2009). Autor and Dorn (2012) emphasize the growth of low-skill personal service jobs at the bottom of the skill distribution. In turn, Goos et al (2011) and Firpo et al (2011) quantify the role that offshoring plays in this polarization.

\section{The Model}

The model consists of two countries, Home and Foreign. The focus is in Home, with analogous equations holding for Foreign. I denote foreign variables with an asterisk. The main innovation of this setup is in modelling of the labor markets. To simplify the exposition, I include only labor as a factor of production in the baseline specification. I postpone the model with capital accumulation to Appendix A. In the baseline model, I also assume that countries are symmetric. In Appendix B, I assume that both countries have a different degree of economic development. There, I consider the model dynamics as a scenario in which one developing country grows faster (but at decreasing rate) over a number of years until catching up with the advanced economy in a new balanced-growth path. The models implication are nonetheless similar it both scenarios. In this regard, note that offshoring not only takes place between countries that are at different stages of economic development but also it pales in comparison to the magnitude of the task trade between similar developed countries (see Grossman and Rossi-Hansberg, 2012, for more discussion). Advanced economies routinely engage each other in an intricate web of production-sharing agreements with the same ultimate goal: to find in the world the most efficient expertise and exploit the local specialization. ${ }^{8}$

\footnotetext{
${ }^{8}$ As discussed in this paper, the new Boeing 787 Dreamliner is a good example. Its production involves 43 suppliers spread over 135 sites around the world: wings come from Japan, engines from UK, fuselage from the US, gears from France, and doors
} 
I start with a description of the productive sector and next characterize the household problem. The technical appendix displays the system equations that characterize the equilibrium conditions of the model.

\subsection{Firms}

Take two sectors. The output of the first sector is the consummation of a diverse number of tasks that may be accomplished at home or overseas. For brevity, I refer to this sector as the "tradable" sector. Notice, however, that the logic is different than the one typically attached to the tradable sector (i.e. a sector that produces final goods that can be internationally traded). Here tradability means that some of the tasks needed to produce the final goods may be executed overseas. Workers who accomplish these tasks require some training, with each worker revealing an idiosyncratic productivity level on completion of this training. The second sector comprises personal services that require only unskilled labor as a factor of production. As previously discussed, these services are non-tradable by definition.

\subsubsection{Tradable Sector}

Every period, households may invest in training, thus creating a diversity of occupations. Training requires an irreversible investment (sunk cost). ${ }^{9}$ At the completion of training, the idiosyncratic productivity $\mathbf{z}$ is revealed. This productivity level remains fixed thereafter until an exogenous job destruction shock makes the specific skilled obtained in the training obsolete. Households draw this productivity from a common distribution $\mathcal{F}(\mathbf{z})$ with support on $[1, \infty)$. Labor provided by each occupation is measured in efficiency units, $l_{\mathbf{z}, t}$, which are the product of raw hours, $l_{t}$, and the idiosyncratic productivity index, $\mathbf{z}$ : $l_{\mathbf{z}, t}=\mathbf{z} l_{t}$. The efficiency unit is transformed back into a raw labor unit if the job destruction shock hits. The job destruction shock is independent of the worker's idiosyncratic productivity level, so $\mathcal{F}(\mathbf{z})$ also represents the efficiency distribution for all workers in any point in time.

from Sweden.

${ }^{9}$ The specific functional form of these costs will be discussed in Section 3.2. 
I assume that technology is labor-augmenting. Each efficiency unit, $l_{\mathbf{z}, t}$, used in production benefits from two technological innovations. The first one, $X_{t}$, is a permanent world technology shock, which affects all productive sectors in both countries. This global shock has a unit-root, as in Lubik and Schorfheide (2006), and it warrants a balanced growth for the economy. In addition, a temporary country-specific technology, $\varepsilon_{t}^{Z}$, exists, which affects the tradable sector and evolves as an AR(1) process. Each efficiency unit provided by each occupation can thus be transformed in a productive task, $n_{t}(\mathbf{z})$, as follows:

$$
n_{t}(\mathbf{z})=\left(\varepsilon_{t}^{Z} X_{t}\right) l_{\mathbf{z}, t}=\left(\varepsilon_{t}^{Z} X_{t}\right) \mathbf{z} l_{t}
$$

I assume that each occupation can perform a given set of tasks, $\xi$, which are defined over a continuum of tasks $\Xi$ (i.e. $\xi \in \Xi)$. At any given time, only a subset of these tasks, $\Xi_{t}\left(\Xi_{t} \subset \Xi\right)$, may be demanded by firms in the global labor market and effectively used in production. ${ }^{10}$ The labor input of this sector consists of a compilation of productive tasks, $n_{t}(\mathbf{z}, \xi)$, which, as in Ottaviano et al (2013), are imperfectly substitutable $^{11}: \mathbb{N}_{t}=\left[\int_{\xi \epsilon \Xi_{t}} n_{t}(\mathbf{z}, \xi)^{\frac{\theta-1}{\theta}} d \xi\right]^{\frac{\theta}{\theta-1}}$, where $\theta>1$ is the elasticity of substitution across tasks. Some of these tasks can be executed in the foreign country. The wage bill is $\mathbb{W}_{t}=\left[\int_{\xi \in \Xi_{t}} w_{t}(\mathbf{z}, \xi)^{1-\theta} d \xi\right]^{\frac{1}{1-\theta}}$, where $w_{t}(\mathbf{z}, \xi)$ is the corresponding wage paid to each efficiency unit labor used in production.

In the baseline specification labor is used only in the production of the tradable sector, $Y_{T, t}$. Under constant returns to scale, $Y_{T, t}=\mathbb{N}_{t}$. Therefore, the price of tradable output, $P_{T, t}$, is $P_{T, t}=\mathbb{W}_{t}$. This model characterizes a real economy with no role for nominal variables. For analytical convenience, I take a standard approach and use the price level of the tradable sector as the numeraire $P_{T, t}=\mathbb{W}_{t} \equiv 1$, hence serving as a unit of account.

\footnotetext{
${ }^{10}$ The subset of tasks demanded by foreign companies is $\Xi_{t}^{*} \subset \Xi$, and may differ from $\Xi_{t}$.

${ }^{11}$ This may capture some local specialization in each specific task (see Grossman and Rossi-Hansberg, 2012). Notice that tasks are not substitutable in Grossman and Rossi-Hansberg (2008). Instead, I take the model approach in Ottaviano et al (2013), which assumes a CES specification.
} 


\subsubsection{Personal Services (Non-Tradable) Sector}

This sector provides personal services that are non-tradable by definition. The output of the service sector, $Y_{N, t}$, is a linear function of unskilled labor: $Y_{N, t}=X_{t} L_{N, t}$, where $L_{N, t}$ is an homogenous aggregate of raw (unskilled) labor units that households supply to the service sector and $X_{t}$ is the unit-root global technology shock. The price for unskilled personal services, $P_{N, t}$, is: $P_{N, t}=\frac{w_{\mathbf{u}, t}}{X_{t}}$, where $w_{\mathbf{u}, t}$ is the real wage paid for each unit of raw labor.

\subsubsection{Trade in Tasks and Skill Income Premia}

In a symmetric equilibrium, $w_{t}(\mathbf{z}, \xi)=w_{t}(\mathbf{z},$.$) , stands for every task \xi \in \Xi$. Therefore, the skill premium gap for a unit of labor employed in the domestic tradable sector with respect to a unit of of raw labor in the nontradable service sector, $\pi_{D, t}$, is defined as:

$$
\pi_{D, t}(\mathbf{z}, .)=w_{D, t}(\mathbf{z}, .) n_{D, t}(\mathbf{z}, .)-w_{\mathbf{u}, t} l_{t}
$$

where the subscript $D$ denotes a task executed for the domestic based firm. Some labor tasks can be accomplished in Foreign. These tasks are subject to a melting-iceberg trade $\operatorname{cost}, \tau \geqslant 1$, as well as a fixed outsourcing cost, $f_{o, t}$. The fixed outsourcing costs is paid on a period-by-period basis. For consistency with the economy-wide balanced growth path, these costs are expressed in units of effective raw labor as

follows: $f_{o, t}=\frac{w_{\mathfrak{u}, t}}{\left(\varepsilon_{t}^{Z} X_{t}\right)}\left(X_{t} f_{o}\right)$. Notice that these outsourcing costs must grow at a rate of $X_{t}$ along this path (as all real variables do in this model). The premium gap for a unit of efficient labor that is demanded overseas (denoted with an $X$ subscript) is:

$$
\pi_{X, t}(\mathbf{z}, .)=\left(\mathbb{Q}_{t} w_{X, t}(\mathbf{z}, .) \frac{n_{X, t}(\mathbf{z}, .)}{\varepsilon_{t}^{\tau} \tau}-f_{o, t}\right)-w_{\mathbf{u}, t} l_{t}
$$


Where $\mathbb{Q}_{t}$ the factor-based real exchange rate (or terms of labor). ${ }^{12}$ Here, the wage for outsourced factors is denoted in terms of the foreign numeraire. Due to these outsourcing and melting-iceberg costs, only the most efficient workers have their tasks demanded in Foreign. In other words, a worker's tasks will take part in multinational production as long as productivity $\mathbf{z}$ is above the threshold $\mathbf{z}_{X, t}=\inf \left\{\mathbf{z}: \pi_{X, t}\left(\mathbf{z}_{,}.\right)>\right.$ $0\}$. Workers with productivity above this threshold are regarded as high-skill. Workers with productivity below $\mathbf{z}_{X, t}$ accomplish tasks only for the domestic market and are middle-skill. From a different angle, foreigners will not execute some of these lower productivity tasks because the outsourcing costs fail to justify that execution. Aggregate shocks to productivity, demand or the cost of trade will result in changes to this threshold level.

Idiosyncratic productivity averages Melitz (2003) shows that these productivity weighted averages summarize the productivity distributions relevant for all macroeconomic aggregates. The average productivity of each workers is: $\tilde{\mathbf{z}}_{D, t} \equiv\left[\int_{1}^{\infty} \mathbf{z}^{\theta-1} d \mathcal{F}(\mathbf{z})\right]^{\frac{1}{\theta-1}}$. The average efficiency of a worker whose tasks are used globally is: $\tilde{\mathbf{z}}_{X, t} \equiv\left[\frac{1}{1-\mathcal{F}\left(\mathbf{z}_{x, t}\right)} \int_{\mathbf{z}_{x, t}}^{\infty} \mathbf{z}^{\theta-1} d \mathcal{F}(\mathbf{z})\right]^{\frac{1}{\theta-1}}$. This setup is isomorphic to one where a mass of workers, $N_{D, t}$, with productivity $\tilde{\mathbf{z}}_{D, t}$ executes tasks in the domestic market, and a mass of workers, $N_{X, t}$, with productivity $\tilde{\mathbf{z}}_{X, t}$ also accomplish tasks that serve as an input for foreign firms. We can define average wages for each of these skill groups as follows: $\tilde{w}_{D, t}=w_{D, t}\left(\tilde{\mathbf{z}}_{D, t} ..\right)$ and $\tilde{w}_{X, t}=w_{X, t}\left(\tilde{\mathbf{z}}_{X, t},.\right)$. Similarly, the average skill-income gap for labor employed domestically is $\tilde{\pi}_{D, t}=\pi_{D, t}\left(\tilde{\mathbf{z}}_{D, t} ..\right)$ while the corresponding outsource skill premia is $\tilde{\pi}_{X, t}=\pi_{X, t}\left(\tilde{\mathbf{z}}_{X, t},.\right)$. Taking these factors into account, the wage bill of the tradable sector, $\mathbb{W}_{t}$, can be redefined as: $\mathbb{W}_{t}=\left[N_{D, t}\left(\tilde{w}_{D, t}\right)^{1-\theta}+N_{X, t}^{*}\left(\tilde{w}_{X, t}^{*}\right)^{1-\theta}\right]^{\frac{1}{1-\theta}}$, where asterisks identify foreign variables.

\footnotetext{
${ }^{12}$ That is, $Q_{t}=\frac{\varepsilon \mathbb{W}_{t}^{*}}{\mathbb{W}_{t}}$ ( $\varepsilon$ is the nominal exchange rate, units of the home numeraire per units of the foreign one). In the baseline specification, $P_{T, t}=\mathbb{W}_{t}$; therefore $\mathbb{Q}_{t}$ also may be interpreted as the terms of trade. The empirically relevant consumption-based real exchange rate measure is defined in the next section. Regarding the nominal exchange rate, $\varepsilon$, note that money must solely be interpreted as a unit of account. Prices are flexible, and money plays no other role in the economy.
} 


\subsection{Households}

I do not address distributional issues in this model. As common in the literature, I assume that household members perfectly insure each other against fluctuations in labor income resulting from changes in employment status, thus eliminating any type of ex-post heterogeneity across individuals. Following the seminal works of Andolfatto (1996) and Merz (1995), households form an extended family that pools all its income and chooses aggregate variables to maximize expected lifetime utility.

Consumption Composites Household preferences over real consumption, $C_{t}$ are defined by the composite: $C_{t}=\left[\left(\gamma_{c}\right)^{\frac{1}{\rho_{c}}}\left(C_{T, t}\right)^{\frac{\rho_{c-1}}{\rho_{c}}}+\left(1-\gamma_{c}\right)^{\frac{1}{\rho_{c}}}\left(C_{N, t}\right)^{\frac{\rho_{c-1}}{\rho_{c}}}\right]^{\frac{\rho_{c}}{\rho_{c}-1}}$, which comprises consumption of non-tradable personal services $C_{N, t}$, and the final good resulting from the composite of tradable tasks, $C_{T, t}$. The consumer price index, always expressed in terms of the price level of the tradable sector, is:

$$
P_{t}=\left[\left(\gamma_{c}\right)+\left(1-\gamma_{c}\right)\left(P_{N, t}\right)^{1-\rho_{c}}\right] .
$$

No investment demand exists in this version of the model. By definition, $C_{N, t}=Y_{N, t}$. Similarly, since only tasks are traded in this model, $Y_{T, t}=C_{T, t}$.

Household's Decision Problem Households have standard additive separable utility over real consumption, $C_{t}$, and leisure, $1-L_{t}$, where $L_{t}$ is the labor supply. They maximize a standard utility kernel, which is modified to be consistent with a balanced growth-path ${ }^{13}$ :

$$
\mathbb{E}_{t} \sum_{s=t}^{\infty} \beta^{s-t} \varepsilon_{t}^{b}\left[\frac{1}{1-\gamma} C_{t}^{1-\gamma}-a_{n} X_{t}^{1-\gamma} \frac{L_{t}^{1+\gamma_{n}}}{1+\gamma_{n}}\right]
$$

where $\gamma, a_{n}, \gamma_{n}>0 . \varepsilon_{t}^{b}$ is an $\operatorname{AR}(1)$ shock to the intertemporal rate of substitution, which may be interpreted as a demand shock.

For simplicity's sake, the period budget constraint is expressed in terms of tradable output, or indis-

\footnotetext{
${ }^{13}$ See, for instance, Rudebusch and Swanson (2012).
} 
tinctly, in units of the wage bill, $\mathbb{W}_{t}$ :

$$
w_{\mathbf{u}, t} L_{t}+N_{D, t} \tilde{\pi}_{t}+B_{t-1}=P_{t} C_{t}+q_{t} B_{t}+\Phi\left(B_{t}\right)+f_{e, t} N_{e, t}
$$

where $\tilde{\pi}_{t}=\left(N_{D, t} \tilde{\pi}_{D, t}+N_{X, t} \tilde{\pi}_{X, t}\right) / N_{D, t}$ is defined as the average skill income premium for all the skilled tasks executed by all workers in Home. Households' total labor income is: $w_{\mathbf{u}, t} L_{t}+N_{D, t} \tilde{\pi}_{t}$. The first term of this expression captures the remuneration from all "raw" units of labor that households supply to the non-tradable service sector as well as the domestic- and foreign- based tradable sector. The second term adds the average skill income premium for all the skilled tasks performed both domestically and outsourced to Foreign. International financial transactions are restricted to one period, risk-free bonds. The level of debt due is $B_{t-1}, q_{t}=1 /\left(1+r_{t}\right)$ is the price of new debt and $r_{t}$ is the implicit interest rate. To induce model stationarity, I introduce an arbitrarily small cost of holding these bonds, $\Phi($.$) , which takes$ the following functional form: $\Phi\left(B_{t}\right)=X_{t} \frac{\phi}{2}\left(\frac{B_{t}}{X_{t}}\right)^{2}$. It is necessary to include the level of world technology both in the numerator and denominator of this functional specification to guarantee stationary along the balanced growth path. ${ }^{14} N_{e, t}$ represents the new skilled occupations created in period $t . f_{e, t}$ is the cost of creating these occupations. Mimicking outsourcing costs, $f_{e, t}$ is expressed in units of effective raw labor and follows a path consistent with balanced-growth: $f_{e, t}=\frac{w_{\mathbf{u}, t}}{\left(\varepsilon_{t}^{Z} X_{t}\right)}\left(X_{t} f_{e}\right)$.

The mass of workers executing tasks for the tradable sector, $N_{D, t}$, evolves according to the following law of motion:

$$
N_{D, t}=(1-\delta)\left(N_{D, t-1}+N_{E, t-1}\right)
$$

The mass of middle-skill workers, $N_{M, t}$, executing tasks exclusively for the domestic firms, is: $N_{M, t}=$ $N_{D, t}-N_{X, t}$

\footnotetext{
${ }^{14}$ In the balanced growth path, debt, $B_{t}$, grows in sync with technology, $X_{t}$, making the ratio stationary. In addition, since all real variables grow at the rate $X_{t}$, I also need to make the adjustment cost grow at the same rate. See Rabanal et al (2011) for further details.
} 
Optimality Conditions Households maximize utility subject to its budget constraint and the law of motion above. The optimality conditions for labor effort and the consumption/saving are reasonably conventional:

$$
\begin{gathered}
a_{n} X_{t}^{1-\gamma} L_{t}\left(C_{t}\right)^{\gamma}=\frac{w_{\mathbf{u}, t}}{P_{t}}, \\
q_{t}=\beta \mathbb{E}_{t}\left\{\frac{\zeta_{t+1}}{\zeta_{t}}\right\}-\Phi^{\prime}\left(B_{t}\right),
\end{gathered}
$$

where $\zeta_{t}=\varepsilon_{t}^{b}\left(C_{t}\right)^{\gamma} / P_{t}$, characterizes the marginal utility of the consumption index. The optimality condition governing the choice of bonds for foreign households in conjunction with the Euler equation in (8) yields the following risk-sharing condition:

$$
\mathbb{E}_{t}\left\{\frac{\zeta_{t+1}^{*}}{\zeta_{t}^{*}} \frac{Q_{t}}{\mathbb{Q}_{t+1}}\right\}=\mathbb{E}_{t}\left\{\frac{\zeta_{t+1}}{\zeta_{t}}\right\}-\frac{\Phi^{\prime}\left(B_{t}\right)}{\beta}
$$

The training optimality condition is pinned down by the following condition:

$$
f_{e, t}=\mathbb{E}_{t} \sum_{s=t+1}^{\infty}[\beta(1-\delta)]^{s-t}\left(\frac{\zeta_{s}}{\zeta_{t}}\right) \tilde{\pi}_{s} .
$$

That is, the training cost incurred to create an occupation in period $t, f_{e, t}$, is evaluated against the present discounted value of the average skill income premium accounted for all the skilled tasks $\left\{\tilde{\pi}_{s}\right\}_{s=t+1}^{\infty}$. Households adjust the discount factor, $\beta$, for the possibility of job destruction, $\delta$, that renders the acquired skills obsolete.

\subsection{Aggregate Accounting and Balanced Trade}

The evolution of the net foreign asset position of this economy is characterized as follows: 


$$
q_{t} B_{t}-B_{t-1}=\mathbb{Q}_{t} N_{X, t}\left(\tilde{w}_{X, t}\right)^{1-\theta} \mathbb{N}_{t}^{*}-N_{X, t}^{*}\left(\tilde{w}_{X, t}^{*}\right)^{1-\theta} \mathbb{N}_{t}
$$

The first term on the right-hand side is the sum of all tasks executed in Home and outsourced to Foreign. The second term reflects the opposite. Finally, home and foreign holdings of risk-free bonds are zero in net supply worldwide: $B_{t}+B_{t}^{*}=0$.

\subsection{Shocks}

The world technology shock has a unit root as in Rabanal and Tuesta (2010): $\log X_{t}=\log X_{t-1}+\eta_{t}^{X}$. Other structural shocks in the model are assumed to follow a $A R(1)$ processes with i.i.d. normal error terms, $\log \varepsilon_{t}^{\hat{\imath}}=\rho^{\hat{\imath}} \log \varepsilon_{t-1}+\eta_{t}^{\hat{\imath}}$, in which $0<\rho^{\hat{\imath}}<0$ and $\eta \sim N\left(0, \sigma^{\hat{\imath}}\right)$, where $\hat{\imath}=\left\{Z, Z^{*}, \tau, \tau^{*}, b, b^{*}\right\}$. As in Lubik and Schorfheide (2006), domestic and foreign technology shocks in tradables $\left(Z, Z^{*}\right)$ are independent. I will evaluate different specifications for the stochastic processes for trade $\left(\tau, \tau^{*}\right)$ and intertemporal rate of substitution $\left(b, b^{*}\right)$. The baseline specification assumes that stochastic innovations in the cost of trading tasks is a global phenomenon that affects countries symmetrically: $\tau=\tau^{*}$. In addition, I assume that innovations to inter-temporal preference are negatively correlated as $\eta_{t}^{b}=-\eta_{t}^{b^{*}}$ in the base case scenario. This process allows for capturing of the "global imbalances" hypothesis, in which the preference for current consumption in one economy (and thus the "desire" to borrow internationally) is matched with an opposite desire to postpone consumption and accumulate foreign assets in the other. These assumptions limit the number of shocks to five. Fewer shocks simplify the model and facilitate its economic interpretation. Nonetheless, I consider alternative specifications in which $\tau, b$ are independent for each country and use the marginal likelihood principle to evaluate whether they fit the data better.

\section{Estimation}

The Bayesian estimation technique uses a general equilibrium approach that addresses the identification problems of reduced form models. It is a system-based analysis that fits the solved DSGE model to a 
vector of aggregate time series (see Fernandez-Villaverde et al., 2004, for additional details). ${ }^{15}$

Data I use several quarterly data series to estimate the model and evaluate its fitness. The data sample used in the estimation covers the period from 1983:Q1 to 2008:Q3. To avoid stochastic singularity, the number of data series used in the estimation cannot exceed the number of shocks in the model. I thus use five aggregate time series: per-capita GDP for the U.S., a similar trade-weighted GDP measure for the rest of the world, and U.S. employment for each of the three skill groups considered within this setup (i.e. high, middle, and low). The structural estimation does not use other historical observables (including consumption, net exports, and the real exchange rate); although the model does use these variables to evaluate the predictions for the covariates obtained with the Kalman smoother. In the estimation, variables are not detrended, but they are seasonally adjusted and expressed in growth rates.

The U.S. Census data displayed in the introduction is not available on a high-frequency basis and cannot be split easily into three distinctive skill groups. Therefore, I use data from the BLS Current Population Survey, aggregated on a quarterly basis, following a similar approach to the one used in Acemoglu and Autor (2011) and Jaimovich and Siu (2012). I consider three categories based on the skill content of the tasks executed by each occupation: Non-Routine Cognitive (high-skill), Routine (middle-skill), and NonRoutine Manual (low-skill). The distinction between cognitive and manual jobs is considered in light of the extent of mental activity needed versus physical activity. The occupation is regarded as routine if one can summarize the tasks involved as a set of specific tasks that must accomplished through the execution of well-defined instructions and procedures. The task is categorized as non-routine if it instead requires flexibility, problem-solving, or human interaction skills. Non-routine cognitive occupations include managers, computer programmers, professionals, and technicians. In the middle of the skill distribution set, we find routine occupations. They include "blue collar" category such as machine operators and assemblers as well as employees who work in data entry, at a help desk, or as administrative supporters. Non-routine manual occupations are primarily service jobs and other manual jobs that require "on-site"

\footnotetext{
${ }^{15}$ See the technical appendix online for details on the data sources, the Bayesian estimation, the comparison of data and model predictions, the variance decomposition, and the Monte Carlo Markov Chain (MCMC).
} 
interactions with the final consumer. The technical appendix lists the exact characterization of jobs. As explained by Jaimovich and Siu (2012), these three categories are closely associated with the rankings in occupational labor income, previously discussed. Fig. 3 depicts the evolution of employment for each skill group in the past three decades, with an historical summary that resembles the one in the introduction. Employment growth is positive for all groups in the 1980s but is monotonic in its skill category. In the 1990s, it distinctly displays a contraction in routine occupations with positive growth in non-routine cognitive and manual occupations. The early 2000s, by constrast are characterized by a robust growth in non-routine manual jobs and a stagnation for the remaining two groups. Notice that this CPS data set is extended through the great recession, which is not included in the last decade of Fig. 2 (constructed with ACS-census data). ${ }^{16}$ The upward trend in these low-skill manual jobs quickly reverses with the onset of the economic crisis in late 2007. Much of this hump-shape in low-skill employment on the diagram reflects the evolution of manual jobs in construction during the housing boom and its subsequent bust.

To make the model comparable with the data, I need the following auxiliary equations. Since variables are expressed in terms of the numeraire $\left(P_{T, t}=\mathbb{W}_{t} \equiv 1\right)$, the empirical counterpart for the real exchange rate requires the conversion of variables in terms of the price of the consumption basket. Define $\varepsilon$ as the nominal price of the consumption basket, then the empirical real exchange rate $\left(R E R_{t}\right)$ is defined as $R E R_{t}=\varepsilon \tilde{P}_{t}^{*} / \tilde{P}_{t}=\varepsilon\left(\mathbb{W}_{t}^{*} P_{t}^{*}\right) /\left(\mathbb{W}_{t} P_{t}\right)=\varepsilon \mathbb{Q}_{t} P_{t}^{*} / P_{t} \cdot{ }^{17}$ The income-based real GDP, $Y_{t}$, also may be expressed in units of the domestic consumption basket with a similar transformation as follows: $Y_{t}=$ $\left(w_{\mathbf{u}, t} L_{t}+N_{D, t} \tilde{\pi}_{t}\right) / P_{t}$

Calibration Some parameters are fixed to solve identification issues due to the limited number of time series that can be used in the structural estimation. They also are calibrated to match sample averages on employment, skills, and U.S. income distribution. The discount factor, $\beta$, takes the standard value of 0.99. Idiosyncratic productivity, z, follows a Pareto distribution with the lower bound fixed at one and

\footnotetext{
${ }^{16}$ Acemoglu and Autor (2011) and Autor and Dorn (2013) use this ACS-Census data and also exclude the Great Recession from their analysis.

${ }^{17} \mathcal{E}$ is the nominal exchange rate: units of the home numeraire per units of the foreign one. Money must be interpreted solely as a unit of account. Prices are flexible, and money plays no other role in the economy.
} 
assumes a shape parameter, $k$, such that $k>\theta-1: \mathcal{F}(\mathbf{z})=1-\left(\frac{1}{\mathbf{z}}\right)^{k}$. Dispersion of the productivity draws is inversely related to $k$. As dispersion decreases, idiosyncratic productivity tends to increasingly concentrate at the lower bound. This lower bound is fixed at one, as the idiosyncratic productivity $\mathbf{z}$ cannot be lower than the unit lower bound attained by the unskilled (raw) labor. In turn, the precise value for the shape parameter, $k$, the symmetric elasticity across tasks used in production, $\theta$, and the offshoring per-period cost, $f_{0}$, are set to match three stylized facts from the data: (1) the ratio of US exports/GDP, which averages 0.13 in the sample period; (2) the ratio of high-skill/middle-skill occupations in total employment (i.e. non-routine cognitive/routine), which averages 0.6 ; and (3) the corresponding ratio of labor income share for each of these two skill groups in the population, which varies between 1.73 and 2.87, depending on the survey method. ${ }^{18}$ The resulting values for $k, \theta$, and $f_{0}$ are 2.36, 1.80, and 0.022 . As standard, the cost of adjusting bond holdings is assigned a negligible value, 0.0035 . The fixed sunk training cost is normalized at one, and the fraction of time households spend working is 0.5 . The share of low-skilled services, $\gamma_{c}$, in the household consumption composite is fixed at 0.25 , to obtain balanced-trade in steady-state. I use a relatively low intra-temporal elasticity of substitution for this composite, $\rho_{c}=0.44$, which is the value Stockman and Tesar (1995) use. The quarterly job-destruction rate, $\delta$, is set at 0.025 , as in Davis and Haltinwanger (1990).

Prior Distributions The remaining parameters are estimated (refer to Table 1). Prior information about the magnitude of the shocks is largely unavailable. Therefore, the variances of all shocks are harmonized as in Smets and Wouters (2007) and assumed to follow an Inverse Gamma distribution that delivers a relative large domain. The auto-regressive parameters in the shocks are assumed to follow a Beta distribution that covers the range between 0 and 1. I fix the prior for the ice-melting trade cost, $\tau$, at

\footnotetext{
${ }^{18}$ Results vary significantly in the different data sources available to measure this last ratio. The first household income source I consider is the BLS Current Population Survey. The survey reports "money income" that includes wages and salaries, interest, dividends, rent and retirement income as well as other tranfers. My baseline model model abstracts from capital, so it is difficult to match each of these income sources to the skill groups in my setup. In addition, the CPS faces other challenges. As explained by Picketty and Saez (2003), this data is not suitable to study the very top of the distribution because of small sample size and top coding of high incomes. For robustness, I also consider Diaz-Gimenez, Glover, and Rios-Rull (2011) that use the Survey of Consumer Finances conducted by the University of Chicago for 1992, 1998, and 2007. Both the "income" indicator that mimics CPS estimates and the "earnings" measure that excludes interest income, dividends, capital gains, and other transfers are considered. In sum, the ratio fluctutates between 1.73 and 2.87 for all the samples considered.
} 
1.40 , as estimated in Novy (2006). In the utility specification, $\gamma_{n}$ is set at 1.33 , so that I obtain a Frisch elasticity of substitution $\left(1 / \gamma_{n}\right)$ that is consistent with the micro estimates in Chetty et al (2012). The prior for the inverse of the elasticity of intertemporal substitution, $\gamma$, is centered at 2 , corresponding with the standard value in the literature.

Estimation Results (Posterior Distributions) The last four columns of Table 1 report the posterior standard deviation, mode, and mean (obtained from the inverse Hessian) along with the 90\% probability interval of the structural parameters. The posterior means for $a_{n}, \gamma, \gamma_{n}, \tau, \tau^{*}$ are 2.57, 0.69, 1.23, 1.25, 1.41. In general, the specified priors were fairly informative. A notable exception is the inverse of the elasticity of inter-temporal substitution, $1 / \gamma$, which indicates a significantly high sensitivity of consumption growth to real interest rates. The AR(1) turned out to be extremely persistent. The stochastic productivity innovations in the domestic tradable sector tend to be relatively more persistent and volatile than those computed for the trade-weighted foreign output.

In the technical appendix, I consider alternative specifications in which the stochastic processes for the trade $\left(\tau, \tau^{*}\right)$ and inter-temporal preferences $\left(b, b^{*}\right)$ are independent. I use the marginal likelihood principle to evaluate which specification fits the data better. The log marginal likelihood difference between the model with independent innovations to intertemporal preference and the baseline economy model is 32.87 , a difference that supports the baseline specification. On other words, the Bayes factor requires a prior probability over the first $\exp (32.87)$ times larger. As discussed in Rabanal and Rubio-Ramírez (2005), this difference can be regarded as sizable. The difference is even larger (132.61) when comparing the baseline with a model in which both trade and preference innovations are independent, further supporting the base case scenario. 


\section{The Effect of Shocks}

I start with an impulse response analysis to interpret the effect that each of the estimated shocks will have in the macroeconomic dynamics. In the next subsection, I make a quantitative assessment of the contribution that each of these shocks will impose on the employment dynamics for each skill group over the sample period.

A Neutral Technology Shock in the Tradable Sector Fig. 4 shows the estimated median impulse responses of key model variables to a transitory technological innovation in the tradable sector of the home economy (one standard deviation) along the $10 \%$ and $90 \%$ posterior intervals. Within the boundaries of this model, the nature of this shock somewhat resembles a skill-biased technological change. As productivity grows steadily in the tradable sector, skilled labor input becomes more productive and as-

sociated wages increase. Consequently, the return to job creation in the middle-to-high skill segment increases, and households react by devoting more resources to training. The substitution effect dictates that consumption demand should move away from the non-tradable service sector towards the tradable sector since this last sector benefited from lower effective costs arising from associated productivity gains. However, the income effect clearly dominates. That is, higher productivity and aggregate income boost the demand for non-tradable services and low-skill employment. The "Harrod-Balassa-Samuelson" effect is in play, as a subdued productivity growth for the service sector results in higher prices (and wages) for non-tradables. Therefore, employment grows for all the skill groups. Notice, however, that an economywide ratio of skilled over unskilled employment increases. That is, job creation in the high-skill group takes a dominant position. As discussed in the introduction, the response of employment to this shock resembles the evolution of job creation in the U.S. during the 1980s.

Wages display a similar pattern. Wages increase for all skill groups, but earnings for the most skilled expand more robustly, resulting in an increase in associated skill premium. The appreciation of home labor costs leads to a factor-based, real exchange rate appreciation that translates into an increase in the 
threshold value $\tilde{\mathbf{z}}_{X, t}$. That is, as wages increase, the international competitiveness of less skilled workers in the tradable sector (lowest $\mathbf{z}$ ) significantly erodes. Therefore, firms engaged in multinational production increasingly hire workers who are at the upper tail of idiosyncratic productivity (therefore justifying the increased wage bill).

A Decline in the Cost of Trading Tasks. Fig. 5 shows the median impulse response of a negative shock to the melting-iceberg trade costs, which are symmetric across both countries. The decline in trading costs (or trade liberalization) induces multinational firms to expand the number of tasks executed abroad. Lower trade costs allow firms to hire the most effective workers in every country, improving the stance of the high-skill individuals worldwide. Trade liberalization triggers a decrease in the offshoring cutoff $\tilde{\mathbf{z}}_{X, t}$, inducing a diverging path for the occupations in the middle-skill cluster. Most of these workers are displaced as they face lower earnings that result from the competition from offshore workers. Nonetheless, lower offshoring costs allow some workers with the highest ability (highest $\mathbf{z}$ ) within this middle-skill cluster to enter the global marketplace, which may be interpreted as a "task upgrade" in the spirit of Ottaviano et al (2013). The net effect of lower trade barriers in employment of the tradable sector is negative. The explanation for this result follows. In autarky, firms need to accomplish locally a variety of tasks executed by a diverse number of occupations. When the economy opens, the need to hire only domestic workers fades. Nonetheless, trade liberalization induces specialization and efficiency gains across countries. This specialization results in gains in measured labor productivity for those engaged in global trade and thus higher aggregate income. ${ }^{19}$ This wealth effect leads to an increasing demand for non-tradable services. Real unskilled wages therefore increase, and employment in this low-skill sector expands. Overall, the decrease in the melting iceberg costs leads to a distinctive labor market polarization with a hollowing out of the middle. Middle-skill workers not only decline in number, but their income share is significantly eroded. Those at the upper and lower tails of the skill distribution not only face

\footnotetext{
${ }^{19}$ Deriving directly from the production function, Ottaviano et al (2013) and Wright (2013) refer to this phenomenon as the "productivity effect" of offshoring.
} 
better employment prospects but also gain a higher share of income. ${ }^{20}$ These results coincide with the emergence of offshoring and labor market polarization witnessed in the 1990s.

An Asymmetric Shock to the Intertemporal Rate of Substitution Fig. 6 shows the effect of an asymmetric shock to the inter-temporal rate a substitution. The foreign economy postpones consumption as its households become relatively more patient, with exactly the opposite occurring in the home country. The implications for the bilateral current account are straightforward: foreigners accumulate net foreign assets by running a protracted trade surplus to finance a consumption boom in the domestic economy. As explained in the introduction, within the boundaries of this stylized model, this pattern is consistent with the experience in the U.S. during the years preceding the Great Recession.

These events have a direct effect on the reallocation of labor across sectors. Household consumption is a composite of two complementary goods. The first goods are non-tradables services that must be executed on the site where the consumer is located. The second goods are produced by workers in the tradable sector, who may execute their labor tasks remotely. As a result, when the shock hits, domestic households devote more of their labor effort to increase the production of services, and they increasingly rely on foreign workers to produce tradable output. Consequently, imports of foreign "tasks" increase. In turn, fewer domestic "tasks" are exported since foreign consumption declines on impact. The tradable sector shrinks as a result. As the non-tradable sector expands, unskilled real wages increase, and relative skilled wages associated to the trading sector fall. Training and job creation decreases, and households reallocate more unskilled labor into the non-tradable sector.

\subsection{Shock Historical Decomposition}

Fig. 7 reports the employment data that I use in the estimation (i.e. quarterly growth rates) as well as the benchmark model's Kalman filtered one-sided predicted values computed at the posterior (which loosely

\footnotetext{
${ }^{20}$ As explained in Ghironi and Melitz (2005), since the shocks are symmetric, there are no movements in relative, cross-country variables such as the terms of trade and the real exchange rate. In the computations, the response of the real exchange is different than zero but quantitatively negligible.
} 
can be interpreted as the in-sample fit). The fit appears to be satisfactory. ${ }^{21}$

Fig. 8 assesses the historical contribution of the estimated shocks to employment for each skill group during the sample period. Variables (the thick red line) are expressed in deviations from the corresponding stationary employment levels in the balanced-growth path. ${ }^{22}$ The quantitative analysis delivers results that are broadly consistent with the historical narrative of this paper. The top panel indicates that during the 1980s, the vast majority of job creation in the high-skill segment comes from technology shocks in the tradable sector (refer to the line with the triangle marker). The model captures the decline in trade (offshoring) costs that starts in the 1990s and persists through the 2000s as documented in Firpo et al (2011). These trade cost innovations (follow the line with the diamond marker) explain the greatest bulk of the solid job creation witnessed by this group during the $1990 \mathrm{~s}^{23}$ Instead, during the 2000s, the discount factor shock that favored low-skill non-tradable tasks (see the thin pink line) acted as a drag on high-skill employment. The negative contribution of this shock explains the leveling-off of this variable during the last years. Inference from the structural estimation indicates suggests a short-lived (but sizable) negative technology innovation affecting the tradable sector occurred in both economies at the start of the crisis in $2008 .^{24}$ But noticeably, high-skill employment in this sector remained largely unaffected thereafter. That is, the synchronized negative innovations had an offsetting effect on employment. As temporary low productivity deters offshoring, high-skilled foreign tasks are substituted with domestic tasks on very short horizons. At the end of sample period, increasing trade costs associated with the crisis can be associated with a moderate decline in employment for this skill group. ${ }^{25}$

The job destruction for the middle-skill cluster that began in the early 1990s and continued during

\footnotetext{
${ }^{21}$ The forecast error variance decomposition is in the technical appendix, where I show that productivity (technology) accounts for most of the variation in output and other real variables in the medium- to lung-run, consistent with the findings in Shapiro and Watson (1988) and Smets and Wouters (2007). Innovations to trade costs and intertemporal substitution play a more dominant role at shorter frequencies.

${ }^{22}$ The presence of a unit-root global technology shock renders the model's real variables as non-stationary. However, employment (and real prices) are stationary in the balance-growth path. In other words, the global unit-root shock does not play any role in this quantitative assessment.

${ }^{23}$ The weight that these shocks carry in explaining the variability of high-skill employment in the 1990 s is $25 \%$ larger than in the 1980 s and $39 \%$ larger than in the 2000s.

${ }^{24}$ Smoothed (two-sided) estimates of all the unobserved shocks are not reported but are available upon request.

${ }^{25} \mathrm{Ahn}$ et al (2011) indicates that financial frictions lead to a trade credit freeze that resulted to increasing trade costs and a notable decline in global trade during the crisis.
} 
the remainder of the sample period, is closely associated with stochastic innovations negatively affecting the cost of offshoring tasks. ${ }^{26}$ In turn, demand shocks (intertemporal rate of substitution) played an important role in variability of middle skill employment during the 2000s. On impact, the demand driven consumption boom that emerged in the early 2000s benefitted the employment of middle-skill occupations which supply tasks used only domestically. But over time, households reduced the amount of training (job creation) in tradable occupations in favor of non-tradable tasks. Finally, domestic tradable productivity (technology) innovations reflected the ups and downs of the business cycle and imposed remarkable depressing effects on middle-skill employment during the three recorded recessions, consistent with the findings in Jaimovich and Siu (2012). Inherently, those losses were magnified during the great recession.

Much of the variability in low-skill, non-tradable employment took place in the last decade. Consistent with the thesis of this paper, the run-up in employment for this group in the early 2000s was the direct byproduct of a sequence of shocks to intertemporal substitution associated with the global imbalances. The striking job destruction in the low-skill cluster at the onset of the Great Recession was the consequence of the reversal of these transitory consumption demand shocks as well as negative aggregate productivity associated with the crisis. Of note, this boom-bust in non-tradable employment coincides with a notable reversal on international borrowing. At the end of 2006, the U.S. current account deficit represented 6.25\% of its GDP. By 2009 that number was only $2.45 \%$.

\section{Model Fit and Business Cycle Properties}

\section{Autocovariance Functions}

As in Adolfson et al. (2007), I assess the model's empirical adequacy by conducting a posterior predictive analysis where actual data are compared to an artificial time series generated from the estimated

\footnotetext{
${ }^{26}$ The weight that these trade cost shocks have in explaining the variability of middle-skill employment in the 1990 s is $35 \%$ larger than in the 1980 s and $48 \%$ larger than in the 2000s. Tradable productivity plays a more relevant role in the 1980 s as its relative weight is $15 \%$ larger than in the susequent decade.
} 
benchmark DSGE model. I compare vector autocovariance functions in the model and the data. The function depicts the covariance of each variable against itself (measured at lags $h=0,1, \ldots 4$ ) and other variables. The vector autocovariance functions are computed by estimating an unrestricted VAR model on the data for the sample period. I include employment for each skill group and domestic output. ${ }^{27}$ Fig. 9 displays the median vector autocovariance function from the DSGE specification (thin lines) along the percentiles of the distribution (dotted lines) that reflect both parameter and sample uncertainty. Data covariances (thick lines) in general fall within the error bands, suggesting that the model adequately mimics the cross-covariances in the data. One notable exception is that the volatility of output from the DSGE specification is significantly larger than the one coming from the actual data. By definition, this also affects the model's prediction for the cross-covariances of output with skill-specific employment variables. ${ }^{28}$

\section{Unconditional Moments}

To avoid stochastic singularity, some key macroeconomic aggregates were not used in the structural estimation (including household consumption, net exports and the real exchange rate). These data series, however, can be used to evaluate the empirical properties of the setup. That is, the Kalman filter can back out the (smoothed) shocks in the model, and these can be utilized to make inferences about the cyclical properties of the simulated aggregate series, which then can be confronted with actual data.

As discussed in Heathcote and Perri (2002), the workhorse international real business cycle (IRBC) setup fails to account for some important features of the data. The literature refers to these well-know empirical shortcomings as "puzzles." Namely, cross-country consumption correlations are generally similar to or lower than cross country output correlations in the data while the IRBC model typically delivers much higher cross-country consumption correlation than output correlation (which tends to be close to zero in simulations). This anomaly is known as the "quantity puzzle". The "international comovement puzzle" reflects that factor inputs (employment and investment) tend to be positively correlated across

\footnotetext{
${ }^{27}$ I draw 3,000 parameter combinations from the posterior distribution and simulate 3,000 artificial data sets of the same length as the data. Then I use the 3,000 data sets to estimate vector autocovariance functions using the same VAR specification applied to the actual data.I use only one lag in the estimated VAR since the data set includes very few observations, and adding an additional lag would significantly reduce the degrees of freedom in the estimation.

${ }^{28}$ By definition, the "correlation" is dimensionless; however the "covariance" is in units obtained by multiplying the units of the two associated variances.
} 
countries whereas the IRBC baseline setup predicts a negative correlation. The real exchange rate is strongly and positively correlated to the ratio of consumption across countries in the IRBC framework (a correlation which is close to one). In the data, however, this correlation is zero or negative. Besides, the standard model generates far less volatility in the RER than in the data. In the literature, these model/data inconsistencies are known as the "Backus-Smith" and "Price" puzzles, respectively. The literature has energetically attempted to bridge this gap between theory and data with some remarkable success. The goal of this paper is not to propose a horse-race between my model and some notable contributions addressing these puzzles but to show how this "trade in tasks" setup can provide new insights on these issues while further validating its empirical adequacy.

Table 2 reports the empirical moments along the 5th and 95th percentiles, comparing them to their unconditional theoretical counterparts. The data is not detrended, and all variables are expressed in growth rates. For completeness, I also report moments for the two alternative specifications for the stochastic processes previously discussed. The "trade in tasks" model does a fairly good job in addressing the afore mentioned puzzles in the international business cycle literature. ${ }^{29}$ First, the cross-country correlation of output growth is quite similar to the correlation for consumption growth: $\operatorname{Corr}\left(\Delta \ln C, \Delta \ln C^{*}\right)=$ $0.64, \operatorname{Corr}\left(\Delta \ln Y, \Delta \ln Y^{*}\right)=0.48$. Concerning the second puzzle, the model mostly delivers positive crosscountry correlation for net job creation for each skill group: $\operatorname{Corr}\left(\Delta \ln N_{X}, \Delta \ln N_{X}^{*}\right)=0.10, \operatorname{Corr}\left(\Delta \ln N_{M}\right.$, $\left.\Delta \ln N_{M}^{*}\right)=0.31$, with the exception of non-tradable employment, $\operatorname{Corr}\left(\Delta \ln N_{M}, \Delta \ln N_{M}^{*}\right)=-0.08$. Notice, however, that results improve significantly when I consider the extended model with physical capital. Not only does this last correlation become positive but also the magnitude of all cross-country employment correlations increases. In addition, the cross-country correlation for investment is positive, as in the data. ${ }^{30}$ These results may be interpreted as follows: In the standard IRBC, the efficient response to a technology shock is to increase factor inputs (capital and labor) in the more productive country. To do so,

\footnotetext{
${ }^{29}$ In this case, the simulated distribution of moments is based on the samples generated with parameters draws from the posterior distribution.

${ }^{30}$ Unfortunately, I do not possess trade-weighted data on foreign consumption, skill-specific employment. If, as proxies for these covariates, I consider data from the Euro area, I obtain $\operatorname{Corr}\left(\Delta \ln C, \Delta \ln C^{*}\right)=0.25 ; \operatorname{Corr}\left(\Delta \ln Y, \Delta \ln Y^{*}\right)=0.31$; $\operatorname{Corr}\left(\Delta \ln I, \Delta \ln I^{*}\right)=0.12 ; \operatorname{Corr}\left(\Delta \ln L, \Delta \ln L^{*}\right)=0.15 ;$ and $\operatorname{Corr}\left(\Delta \ln \left(C-C^{*}\right), \Delta \ln R E R\right)=-0.25$.
} 
this country borrows internationally to finance this activity, which in turn ends up reducing factor inputs and output in the less productive country. This in turn leads to a decrease in factor inputs and outputs correlations. In the "tasks" model, production is the by-product of labor tasks that complement each other but are executed in both countries. If productivity increases in one country, the demand for the complementary foreign tasks will be enhanced with a positive impact on foreign production. Furthermore, job creation involves a sunk cost that adds endogenous persistency to my model, making it more difficult to drastically change the location of factoral inputs in response to transitory changes to cross-country relative productivity. These characteristics increase cross-country correlations for employment, output, and investment inducing the "tasks" model to better address the first two puzzles mentioned.

The "tasks" model also preforms well in addressing the last two puzzles. The correlation in question is: $\operatorname{Corr}\left(\Delta\left(C-C^{*}\right), \Delta R E R\right)=0.19$, with a standard deviation for the real exchange rate growth (2.69), which is closer to that documented in the data (2.43). In the computations, shocks to the intertemporal rate of substitution play a decisive role in addressing these puzzles. As explained in Stockman and Tesar (1995), demand shocks, not present in the IRBC baseline specification, are critical to match this aspect of the data. Finally, the model is able to deliver a countercyclical trade balance, a negative correlation of the trade balance with (non-tradable) low skill consumption. The cyclicality of skill-specific employment is also in line with the data (with the exception of middle-skill employment growth).

\section{Conclusion}

I develop a two-country dynamic stochastic growth model that is distinguished by the presence of trade in tasks rather than in goods. The model uses U.S. employment data for different skill groups and tradeweighted macroeconomics indicators for the U.S. and the rest of the world. In the model, a decrease in the barriers to trade leads to a polarization of the labor market. Lower trade costs and technological advances in communications allow firms to incorporate productive tasks that are executed remotely in different locations. In this context, multinational firms hire the most efficient workers from each country 
and exploit any existing local specialization, thus benefitting the high ability workers. This outsourcing harms the employment prospects of middle-skill workers who must compete with foreigners. Low-skill workers are protected from the offshoring wave because they specialize in the provision of non-tradable services (e.g. child/elderly care, gardening, janitorial work, and construction) that require their tasks to be executed in the same place where the service is provided. Trade leads to more specialization and increases aggregate productivity, further enhancing the demand for non-tradable services and the employment prospects for the low-skilled.

Noteworthy, this employment polarization is not an steady process: the relative employment share of each skill group significantly fluctuated over the last three decades. I show that the estimated aggregate shocks affecting labor productivity, offshoring costs, and consumption demand can rationalize such employment dynamics. Finally, this "trade in tasks" model not only helps to explain the labor polarization but also delivers a more accurate business cycle synchronization (output and factor comovement) and real exchange rate dynamics.

Low-skill service jobs cannot be offshored, but immigration is an alternative. During the past decades, the emergence of these service jobs coincided with an increase in low-skill migration inflows. Immigrants may contain the increase in wages for the low-skilled, thus forcing natives to continue training to acquire additional skills. Future research should further explore the interaction between migration and trade in this context. ${ }^{31}$

\footnotetext{
${ }^{31}$ Ottaviano et al (2013) initiated this interesting research agenda.
} 


\section{A Appendix-Model with Capital}

As in Bilbiie (2012), I introduce capital in the extended model. Household's capital accumulation follows the specification in Mandelman et al (2011):

$$
K_{t}=\left(1-\delta^{k}\right) K_{t-1}+\varepsilon_{t}^{V}\left(I_{t}-\frac{\phi^{k}}{2} I_{t-1} \frac{\varepsilon_{t-1}^{V}}{\varepsilon_{t}^{V}}\left[\frac{I_{t} \varepsilon_{t}^{V}}{I_{t-1} \varepsilon_{t-1}^{V}}-\Lambda_{X}\right]^{2}\right)
$$

where $\varepsilon_{t}^{V}$ represents the Investment-Specific Technology Shock. These stochastic innovations follow the same $\mathrm{AR}(1)$ specification previously characterized. In a competitive equilibrium, $\left(\varepsilon_{t}^{V}\right)^{-1}$ may be interpreted as the relative price of capital goods with respect to the price of consumption goods. The adjustment cost must be rescaled to account for the long-run gross rate of growth of investment along the balanced growth path: $\Lambda_{X}$. The parameter, $\phi^{k}$, controls the elasticity of the adjustment cost to the capital stock in response to changes in investment. $\delta^{k}$ is the rate of depreciation.

The budget constraint becomes:

$$
w_{\mathbf{u}, t} L_{t}+N_{D, t} \tilde{\pi}_{t}+B_{t-1}+\left(1+r_{t}^{k}\right) K_{t-1}=P_{t}\left(C_{t}+I_{t}\right)+q_{t} B_{t}+\Phi\left(B_{t}\right)+f_{e, t} N_{e, t}
$$

where $r_{t}^{k}$ is the rental rate of capital. The first-order conditions with respect to capital and investment deliver:

$$
\lambda_{t}=\beta \mathbb{E}_{t}\left\{\left(1+r_{t+1}^{k}\right) \zeta_{t+1}+\lambda_{t+1}\left(1-\delta^{k}\right)\right\}
$$

and

$$
P_{t} \zeta_{t}=\lambda_{t} \varepsilon_{t}^{V}\left(1-\phi^{k} \Omega_{t}\right)+\beta \mathbb{E}_{t}\left\{\lambda_{t+1} \varepsilon_{t+1}^{V}\left[\phi^{k} \Omega_{t+1} \frac{I_{t+1}}{I_{t}}-\frac{\phi^{k}}{2} \frac{\varepsilon_{t}^{V}}{\varepsilon_{t+1}^{V}}\left(\Omega_{t+1}\right)^{2}\right]\right\}
$$

where $\Omega_{t+1}=\frac{I_{t} \varepsilon_{t}^{V}}{I_{t-1} \varepsilon_{t-1}^{V}}-\Lambda_{X}$

On the firm side, production in the tradable sector is a CES composite of labor and capital.

$$
Y_{t}^{T}=\left[\alpha K_{t-1}^{\frac{\sigma-1}{\sigma}}+(1-\alpha) N_{t}^{\frac{\sigma-1}{\sigma}}\right]^{\frac{\sigma}{\sigma-1}}
$$


The first-order condition for physical capital and the labor composite is: $(1-\alpha)\left(\frac{Y_{t}}{N_{t}}\right)^{\frac{1}{\sigma}}=\frac{1}{P_{t}^{T}} ; \alpha\left(\frac{Y_{t}}{K_{t-1}}\right)^{\frac{1}{\sigma}}=$ $\frac{\left(1+r_{t}^{k}\right)}{P_{t}^{T}}$, respectively. ${ }^{32}$

An Investment-Specific Technology Shock Fig. A1 displays the median response to an InvestmentSpecific Technology (IST) shock in the Home economy along the $10 \%$ and $90 \%$ confidence intervals. ${ }^{33}$ Following the shock, the relative price of investment goods declines and domestic firms expand their capital equipment. Since production becomes more capital intensive, the relative productivity of the labor force employed in the tradable sector also increases. These productivity gains asymmetrically impact domestic workers. On one hand, more efficient multinational firms can now afford to pay increasing offshoring costs to hire more of the most productive foreign labor inputs, resulting in a negative impact on the earnings of low ability workers (low z) in Home. On the other hand, those workers who remain employed become more productive, reaping benefits both from domestic and foreign markets. The subsequent positive income effect translates into an increasing demand for low-skill services. Since the non-tradable sector only uses labor as a factor of production, it is not directly affected by these IST innovations. Thus, this increasing demand translates into higher unskilled wages. Households react by reducing the amount of training (job creation) aimed at the tradable sector.

Interestingly, the IST shock hitting the domestic economy also leads to more capital accumulation in Foreign. Home firms become more productive and can pay higher wages to high-ability foreign workers executing tasks for Home. Thus, for foreign firms, their labor input becomes more expensive due to free arbitrage. They proceed by accumulating capital to attain a productivity level that justifies paying these higher wages.

Overall, the worldwide effect of these IST shocks is to enhance the polarization. Production in tradables is more capital intensive. Firms in this sector hire fewer workers, but they can become more selective, increasingly hiring only the most effective workers in the world. In turn, the middle-skill employees

\footnotetext{
${ }^{32}$ The numeraire is $\mathbb{W}_{t} \equiv 1$. When we introduce capital, the identity, $P_{t}^{T} \equiv \mathbb{W}_{t}$, no longer holds.

${ }^{33}$ Estimation results for this complete model can be found in a separate technical appendix. In the calibration, the depreciation of capital, $\delta^{k}$, and its share in production, $\alpha$, take the standard value of 0.025 and 0.40 , respectively. The elasticity of substitution, $\sigma$, is fixed at 0.52 (as estimated in Raval, 2013). Capital adjustment costs, $\phi^{k}$, are estimated with a prior fixed at 0.5 .
} 
fare worse, and the employment and earnings for the low-skilled are enhanced. 


\section{B Appendix-Trade Between Asymmetric Countries}

Here I consider the case of countries displaying asymmetric balanced growth paths, which tend to converge over time. This case also may be interpreted as a situation in which countries are originally at different stages of economic development but eventually catch up to each other. In keeping with the Balassa-Samuelson hypothesis, I assume that the relative productivity of the tradable sector of one country with respect to the other grows at an increasing rate until reaching a new balanced growth path. For simplicity's sake, I assume that forward-looking agents anticipate the long-run dynamics of relative productivity with perfect foresight. As in Ravenna and Natalucci (2008), I add the future values of the deterministic balanced growth path to the list of state variables. All real variables in both countries grow at a rate, $X_{t}$, in the common new balanced growth path. The horizon over which the productivity growth in one country exceeds the other is limited to five years to avoid explosive paths in model simulations (that must rely on second-order approximations).

For model comparison, I consider two scenarios in Fig. A2. First, I depict a once-and-for-all 1\% productivity innovation in tradables that shifts the underdeveloped economy to the new balanced growth on impact (clear solid line). In the second scenario, I assume that relative productivity increases steadily at a decreasing rate over a period of 5 years-20 quarters-until both countries converge to the new balanced growth path (dashed line). The dark solid straight line displays the permanent change from the original balanced growth to the final. In Foreign, the permanent change to relative productivity results in positive employment growth for all the skill groups in the new balanced growth path. These changes are qualitatively similar to the case of transitory innovations with symmetric economies previously discussed. In the new stationary equilibrium, the catching up of the developing country leads to employment polarization in Home.

In the case of a slow convergence, Foreign fully anticipates future (and permanent) productivity growth, which takes time to materialize. As predicted by the permanent-income hypothesis, the foreign economy borrows from Home. As a result, Foreign biases its production structure towards non-tradables 
and increasingly relies on Home to provide for tradable tasks. Increasing exports of tasks at Home temporarily benefits relatively high-skill domestic workers and some of those with middle-skill ability (high z) who can enter the global market. As Home lends to Foreign, household consumption is temporarily depressed, and non-tradable service employment declines. Over time, however, Home converges to a new stationary equilibrium in which low-skill employment actually increases. Once all the adjustments take place, Home benefits from the increase in productivity in complementary foreign tasks. Consequently, aggregate productivity, income, and consumption increase, ultimately improving the prospects of the non-tradable sector at Home. 


\section{References}

[1] Acemoglu, Daron. 1999. Changes in Unemployment and Wage Inequality: An Alternative Theory and Some Evidence. American Economic Review 89: 1259-1278.

[2] Acemoglu, Daron and David Autor. 2011. Skills, Tasks and Technologies: Implications for Employment and Earnings. in O. Ashenfelter and D. Card, eds. Handbook of Labor Economics, Vol. 4.

[3] Adolfson, Malin; Stefan Laseen; Jesper Linde; and Mattias Villani. 2007. Bayesian estimation of an open economy DSGE model with incomplete pass-through. Journal of International Economics 72: 481-511.

[4] Ahn, JaeBin; Mary Amiti; and David Weinstein. 2011. Trade Finance and the Great Trade Collapse. American Economic Review 101: 298-302.

[5] Andolfatto, David. 1996. Business Cycles and Labor-Market Search. American Economic Review 86: 112-32.

[6] Autor, David; Lawrence Katz; and Melissa Kearney. 2006. The Polarization of the U.S. Labor Market. American Economic Review 96, 189-194.

[7] Autor, David and David Dorn. 2012. The Growth of Low Skill Service Jobs and the Polarization of the U.S. Labor Market. American Economic Review, forthcoming.

[8] Bilbiie, Florin; Fabio Ghironi; and Marc Melitz. 2012. Endogenous Entry, Product Variety, and Business Cycles. Journal of Political Economy 120: 304-345.

[9] Blanchard, Emily and Gerald Willmann. 2013. Trade, Education and the Shrinking Middle Class, mimeo. Dartmouth College.

[10] Burstein, Ariel and Jonathan Vogel. 2012. International Trade, Technology and the Skill Premium. UCLA, mimeo.

[11] Cacciatore, Matteo. 2013. International Trade and Macroeconomic Dynamics with Labor Market Frictions, mimeo.

[12] Chetty, Raj; Adam Guren; Day Manoli and Andrea Weber. 2012. Does Indivisible Labor Explain the Difference Between Micro and Macro Elasticities? A Meta-analysis of Extensive Margin Elasticities. NBER Macroeconomics Annual 2012, 27.

[13] Costinot, Arnaud and Jonathan Vogel. 2010. Matching and Inequality in the World Economy. Journal of Political Economy: 118 747-786.

[14] Davis, Steven and John Haltiwanger. 1990. Gross Job Creation and Destruction: Microeconomic Evidence and Macroeconomic Implications. NBER Macroeconomics Annual 5: 123-186.

[15] Díaz-Giménez, Javier; Andy Glover; and José Ríos-Rull. 2011. Facts on the Distributions of Earnings, Income, and Wealth in the United States: 2007 Update. Federal Reserve Bank of Minneapolis Quarterly Review 34: 2-31.

[16] Fernández-Villaverde, Jesús and Juan Rubio-Ramírez. 2004. Comparing dynamic equilibrium models to data: a Bayesian approach. Journal of Econometrics 123: 153-0187.

[17] Firpo, Sergio; Nicole Fortin; and Thomas Lemieux. 2011. Occupational Tasks and Changes in the Wage Structure. University of British Columbia, mimeo. 
[18] Ghironi, Fabio and Marc Melitz. 2005. International Trade and Macroeconomic Dynamics with Heterogeneous Firms. Quarterly Journal of Economics 120: 865-915.

[19] Goldberg, Pinelopi and Nina Pavcnik. 2007. Distributional Effects of Globalization in Developing Countries. Journal of Economic Literature 45(1): 39-82.

[20] Goos, Maarten and Alan Manning. 2007. Lousy and Lovely Jobs: The Rising Polarization of Work in Britain. The Review of Economics and Statistics 89: 118-133.

[21] Goos, Maarteen; Alan Manning; Anna Salomons. 2009. Job Polarization in Europe. American Economic Review 99, 58-63.

[22] Goos, Maarten; Alan Manning; Anna Salomons. 2011. Explaining Job Polarization : The Roles of Technology, Offshoring and Institutions. University of Leuven.

[23] Grossman, Gene and Esteban Rossi-Hansberg. 2008. Trading Tasks: A Simple Theory of Offshoring. American Economic Review 98: 1978-1997.

[24] Grossman, Gene and Esteban Rossi-Hansberg. 2012. Task Trade Between Similar Countries. Econometrica 98: 1978-1997.

[25] Han, Jun; Runjuan Liu; and Junsen Zhang. 2012. Globalization and wage inequality: Evidence from Urban China. Journal of International Economics 87: 288-297.

[26] Heathcote, Jonathan and Fabrizio Perri. 2002. Financial autarky and international business cycles. Journal of Monetary Economics 49: 601-627.

[27] Helpman, Elhanan; Oleg Itskhoki; and Stephen Redding. 2010a. Inequality and Unemployment in a Global Economy. Econometrica 78: 1239-1283.

[28] Helpman, Elhanan; Oleg Itskhoki; and Stephen Redding. 2010b. Unequal Effects of Trade on Workers with Different Abilities. Journal of the European Economic Association 8: 421-433.

[29] Jaimovich, Nir and Henry Siu. 2012. The Trend Is the Cycle: Job Polarization and Jobless Recoveries. NBER WP 18334.

[30] Kehoe,Timothy; Kim Ruhl and Joseph Steinberg. 2013. Global Imbalances and Structural Change in the United States. NBER WP19339.

[31] Lubik, Thomas and Frank Schorfheide. 2006. A Bayesian Look at the New Open Economy Macroeconomics. NBER Macroeconomics Annual 2005, Vol. 20: 313-382.

[32] Mandelman, Federico; Pau Rabanal; Juan Rubio-Ramírez; and Diego Vilán. 2011. InvestmentSpecific Technology Shocks and International Business Cycles: An Empirical Assessment. Review of Economic Dynamics 14 136-155.

[33] Melitz, Marc. 2003. The Impact of Trade on Intra-Industry Reallocations and Aggregate Industry Productivity. Econometrica 71: 1695-1725.

[34] Merz, Monika. 1995. Search in the Labor Market and the Real Business Cycle. Journal of Monetary Economics 36: 269-300.

[35] Novy, Dennis. 2006. Is the Iceberg Melting Less Quickly? International Trade Costs after World War II. TWERPS 764, University of Warwick.

[36] Ottaviano, Gianmarco; Giovanni Peri; and Greg Wright. 2013. Immigration, Offshoring, and American Jobs. American Economic Review 103: 1925-59. 
[37] Piketty, Thomas and Emmanuel Saez. 2003. Income Inequality In The United States, 1913-1998. Quarterly Journal of Economics 118: 1-39.

[38] Rabanal, Pau and Juan Rubio-Ramírez. 2005. Comparing New Keynesian Models of the Business Cycle: A Bayesian Approach. Journal of Monetary Economics 52: 1151-1166..

[39] Rabanal, Pau; Juan Rubio-Ramírez; and Vicente Tuesta. 2011. Cointegrated TFP Processes and International Business Cycles. Journal of Monetary Economics 58: 156-171.

[40] Rabanal, Pau and Vicente Tuesta. 2010. Euro-dollar Real Exchange Rate Dynamics in an Estimated Two-Country Model: an Assessment. Journal of Economic Dynamics and Control 34: 780-797.

[41] Raval, Devesh. 2013. Non Neutral Technology Differences, mimeo. Federal Trade Commission.

[42] Ravenna, Federico and Fabio Natalucci. 2008. Monetary Policy Choices in Emerging Market Economies: The Case of High Productivity Growth. Journal of Money, Credit and Banking 40: 243-271.

[43] Rudebusch, Glenn and Eric Swanson. 2012. The Bond Premium in a DSGE Model with Long-Run Real and Nominal Risks. American Economic Journal: Macroeconomics 4: 105-43.

[44] Ottaviano, Gianmarco; Giovanni Peri; and Greg Wright. 2013. Immigration, Offshoring, and American Jobs. American Economic Review 103: 1925-59.

[45] Piketty, Thomas and Emmanuel Saez, 2003. Income Inequality In The United States, 1913-1998. Quarterly Journal of Economics 118: 1-39.

[46] Shapiro, Matthew and Mark Watson. 1988. Sources of Business Cycle Fluctuations. NBER Macroeconomics Annual 1988: 111-48.

[47] Smets, Frank and Rafael Wouters. 2007. Shocks and Frictions in US Business Cycles: A Bayesian DSGE Approach. American Economic Review 97: 586-606.

[48] Stockman, Alan and Linda Tesar. 1995. Tastes and Technology in a Two-Country Model of the Business Cycle: Explaining International Comovements. American Economic Review 85: 168-85.

[49] Wright, Greg. 2013. Revisiting the Employment Impact of Offshoring. University of Essex, mimeo.

[50] Zlate, Andrei. 2012. Offshore Production and Business Cycle Dynamics with Heterogeneous Firms. IFDP 995, Federal Reserve System. 
Table 1: Prior and posterior distributions of estimated parameters, model without capital

\begin{tabular}{|c|c|c|c|c|c|c|c|c|}
\hline \multirow[b]{2}{*}{ Description } & \multicolumn{4}{|c|}{ Prior distribution } & \multicolumn{4}{|c|}{ Posterior distribution } \\
\hline & Name & Density & Mean & Std Dev & Mode & Mean & $10 \%$ & $90 \%$ \\
\hline Weight leisure & $a_{n}$ & Gamma & 2.78 & 0.2 & 2.7282 & 2.5692 & 2.3331 & 2.8093 \\
\hline Elast. Intert. Subst. & $\gamma$ & Gamma & 2 & 0.3 & 0.6367 & 0.6860 & 0.6478 & 0.7398 \\
\hline Elast. Labor Supply & $\gamma_{n}$ & Gamma & 1.33 & 0.3 & 1.1829 & 1.2274 & 0.9507 & 1.5286 \\
\hline Ice Melting $(\mathrm{H})$ & $\tau$ & Gamma & 1.40 & 0.15 & 1.2549 & 1.2504 & 1.0992 & 1.4042 \\
\hline Ice Melting $(\mathrm{F})$ & $\tau^{*}$ & Gamma & 1.40 & 0.15 & 1.4107 & 1.4136 & 1.2912 & 1.5374 \\
\hline Tech. shock $(\mathrm{H})$ & $\rho_{z}$ & Beta & 0.5 & 0.2 & 0.9949 & 0.9927 & 0.9909 & 0.9951 \\
\hline Tech. shock (F) & $\rho_{z^{*}}$ & Beta & 0.5 & 0.2 & 0.8330 & 0.8017 & 0.7737 & 0.8287 \\
\hline Trade cost shock & $\rho_{\tau}$ & Beta & 0.5 & 0.2 & 0.9947 & 0.9919 & 0.9861 & 0.9970 \\
\hline Demand shock $(\mathrm{H})$ & $\rho_{b}$ & Beta & 0.5 & 0.2 & 0.9352 & 0.9316 & 0.9278 & 0.9344 \\
\hline Demand shock $(\mathrm{F})$ & $\rho_{b^{*}}$ & Beta & 0.5 & 0.2 & 0.9583 & 0.9519 & 0.9462 & 0.9590 \\
\hline Tech. shock $(\mathrm{H})$ & $\sigma_{z}$ & Inv gamma & 0.01 & $2^{*}$ & 0.0410 & 0.0424 & 0.0370 & 0.0479 \\
\hline Tech. shock (F) & $\sigma_{z^{*}}$ & Inv gamma & 0.01 & $2^{*}$ & 0.0320 & 0.0320 & 0.0269 & 0.0375 \\
\hline Trade cost shock & $\sigma_{\tau}$ & Inv gamma & 0.01 & $2^{*}$ & 0.0055 & 0.0061 & 0.0055 & 0.0067 \\
\hline Demand shock & $\sigma_{b}$ & Inv gamma & 0.01 & $2^{*}$ & 0.0103 & 0.0110 & 0.0098 & 0.0123 \\
\hline Global tech. shock & $\sigma_{x}$ & Inv gamma & 0.01 & $2^{*}$ & 0.0256 & 0.0261 & 0.0237 & 0.0285 \\
\hline
\end{tabular}


Table 2: Unconditional Moments

\begin{tabular}{|c|c|c|c|c|c|c|}
\hline Variables(growth) & $\operatorname{Corr}(H S, G D P)$ & $\operatorname{Corr}(M S, G D P)$ & $\operatorname{Corr}(L S, G D P)$ & $\operatorname{Corr}(L S, C)$ & \multicolumn{2}{|c|}{$\operatorname{Corr}(L S$, NetExp/GDP) } \\
\hline \multirow[t]{2}{*}{ Data } & $\begin{array}{c}0.32 \\
(0.17 / 0.46) \\
\end{array}$ & $\begin{array}{c}0.60 \\
(0.49 / 0.69) \\
\end{array}$ & $\begin{array}{c}0.39 \\
(0.25 / 0.52) \\
\end{array}$ & $\begin{array}{c}0.25 \\
(0.9 / 0.39) \\
\end{array}$ & \multicolumn{2}{|l|}{$\begin{array}{c}-0.23 \\
(-0.37 /-0.07)\end{array}$} \\
\hline & $\operatorname{Corr}\left(N_{X}, Y\right)$ & $\operatorname{Corr}\left(N_{M}, Y\right)$ & $\operatorname{Corr}\left(L_{N}, Y\right)$ & $\operatorname{Corr}\left(L_{N}, C\right)$ & \multicolumn{2}{|l|}{$\operatorname{Corr}\left(L_{N}, \operatorname{NetExp} / Y\right)$} \\
\hline Baseline & 0.17 & -0.03 & 0.30 & 0.49 & \multicolumn{2}{|l|}{-0.46} \\
\hline Indep DF & 0.10 & 0.01 & 0.27 & 0.49 & \multicolumn{2}{|l|}{-0.35} \\
\hline Indep DF \& Trade & 0.08 & 0.01 & 0.26 & 0.48 & \multicolumn{2}{|l|}{-0.36} \\
\hline Variables(growth) & $\operatorname{Corr}\left(G D P, G D P^{*}\right)$ & $\operatorname{Corr}(G D P,(\mathrm{~N}$ & $\mathrm{tExp} / \mathrm{GDP}))$ & $\operatorname{Corr}(G D P, C)$ & $\operatorname{Corr}(C, R E R) \quad \operatorname{Corr}$ & $\left(\frac{C}{C^{*}}, R E R\right)$ \\
\hline \multirow[t]{2}{*}{ Data } & $\begin{array}{c}0.59 \\
(0.48 / 0.68) \\
\end{array}$ & \multicolumn{2}{|c|}{$\begin{array}{c}-0.33 \\
(-0.46 /-0.18) \\
\end{array}$} & $\begin{array}{c}0.71 \\
(0.62 / 0.78) \\
\end{array}$ & \multicolumn{2}{|l|}{$\begin{array}{c}-0.03 \\
(-0.19 / 0.31)\end{array}$} \\
\hline & $\operatorname{Corr}\left(Y, Y^{*}\right)$ & \multicolumn{2}{|c|}{$\operatorname{Corr}(Y, \operatorname{NetExp} / Y)$} & $\operatorname{Corr}(Y, C)$ & $\operatorname{Corr}(C, R E R) \quad \operatorname{Corr}($ & $\left(\frac{C}{C^{*}}, R E R\right)$ \\
\hline Baseline & 0.48 & \multicolumn{2}{|c|}{-0.57} & 0.90 & -0.29 & 0.19 \\
\hline Indep DF & 0.47 & \multicolumn{2}{|c|}{-0.60} & 0.90 & -0.31 & 0.09 \\
\hline Indep DF \& Trade & 0.47 & \multicolumn{2}{|c|}{-0.60} & 0.90 & -0.32 & 0.07 \\
\hline
\end{tabular}

\begin{tabular}{lcccccc}
\hline \hline Variables(growth) & $\operatorname{Corr}\left(Y, Y^{*}\right)$ & $\operatorname{Corr}\left(C, C^{*}\right)$ & $\operatorname{Corr}\left(I, I^{*}\right)$ & $\operatorname{Corr}\left(N_{X}, N_{X}^{*}\right)$ & $\operatorname{Corr}\left(N_{M}, N_{M}^{*}\right)$ & $\operatorname{Corr}\left(L_{N}, L_{N}^{*}\right)$ \\
\hline Baseline & 0.48 & 0.64 & - & 0.10 & 0.31 & -0.08 \\
Indep DF & 0.47 & 0.70 & - & 0.10 & 0.37 & 0.07 \\
Model with Capital & 0.59 & 0.60 & 0.86 & 0.52 & 0.95 & 0.75 \\
Indep DF & 0.42 & 0.95 & 0.60 & 0.18 & 0.22 \\
\hline \hline
\end{tabular}

Note:All Variables are transformed in $\Delta \ln$ and thus expressed in growth rates. The sample period for the data is 1983:2-2009:4. The 5th and 95th percentiles are included in parentheses. For the estimated model, I report the the simulated distribution of moments generated with the median of the posterior distribution of the parameter draws. $\left(^{*}\right)$ Comparable trade-weighted consumption, employment and invesment data for the rest of the world is not available. A comparable indicator computed with data from the Euro area is $\operatorname{Corr}\left(\left(\Delta \ln C-\Delta \ln C^{*}\right), \Delta \ln R E R\right)=-0.25$. Refer to the text, for additional moments computed with the Euro data. 
Figure 1- Changes in US employment by skill percentiles since 1980

Panel A

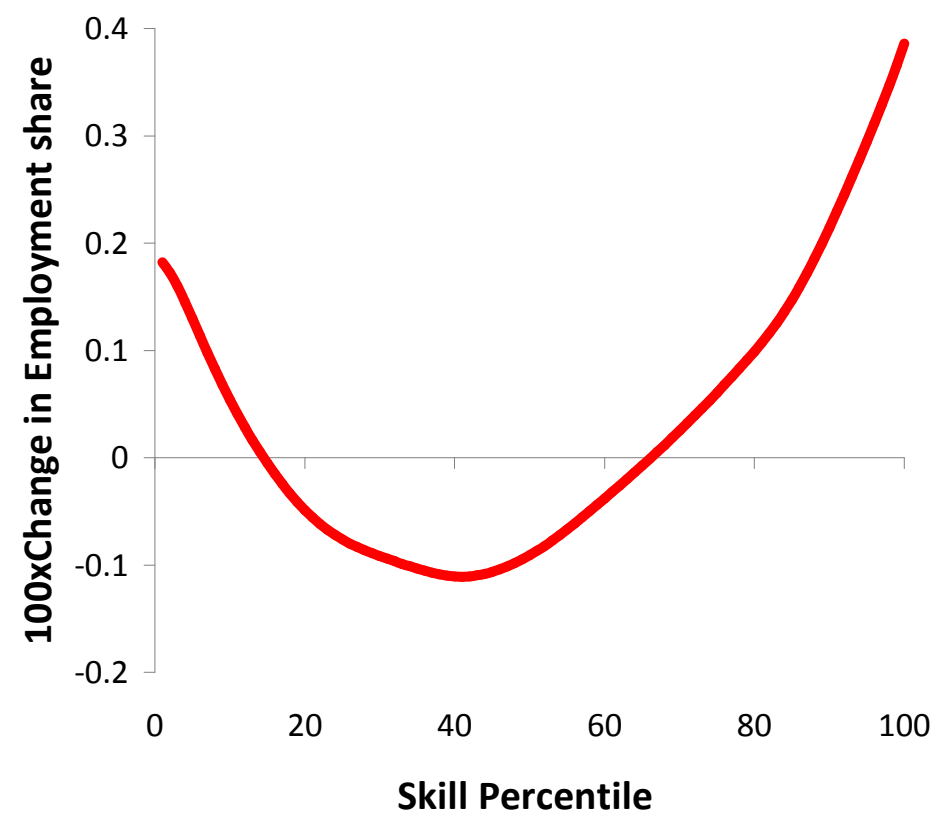

Panel B

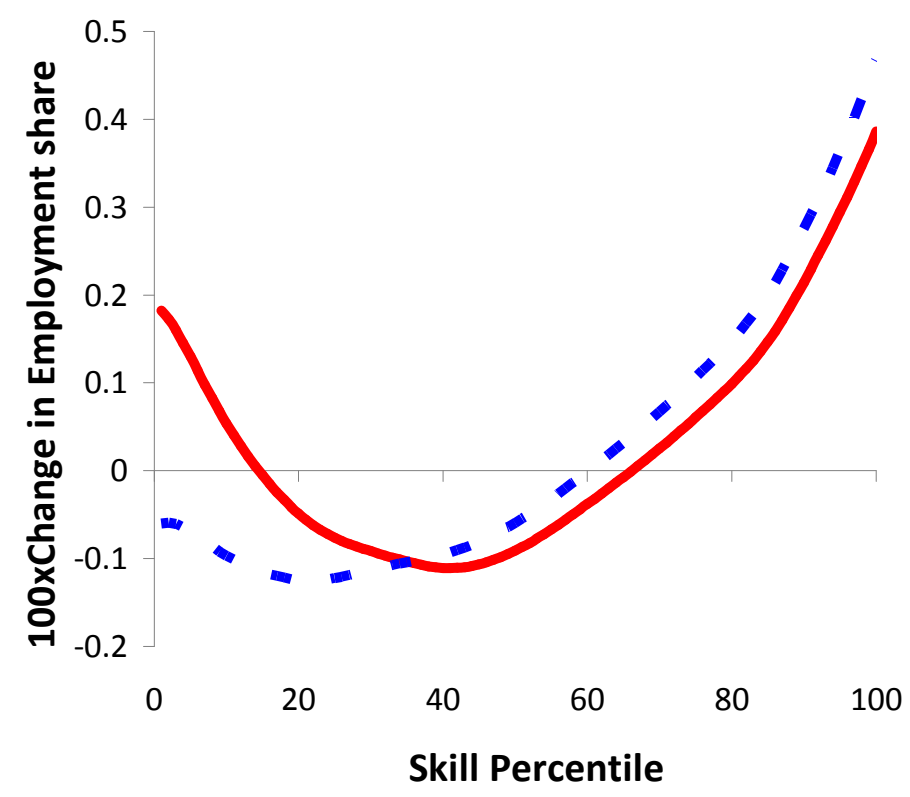

- Holding Services emp at 1980

Note: Smoothed changes in employment. Skill percentile is ranked by occupational mean wage in 1980. In Panel B, the dashed blue line indicates that service employment is held constant at the observed level in 1980. See data appendix for details.

Figure 2- Changes in US employment by skill percentiles for different decades

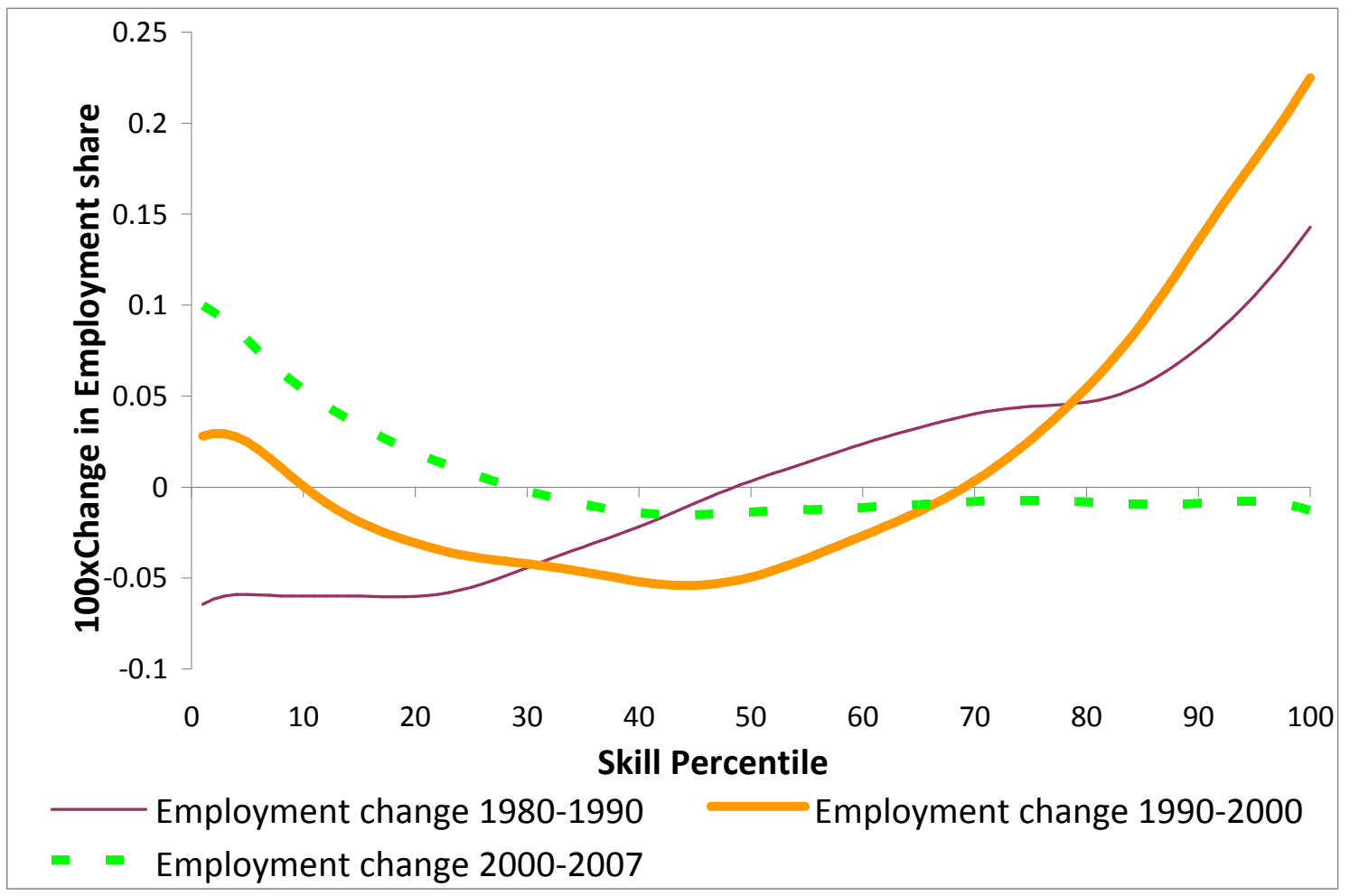

Note: Refer to Fig. 1 for details. Changes over each of the last three decades are displayed. 
Figure 3- Employment by occupation groups (High-Skill, Middle-Skill, Low-Skill)
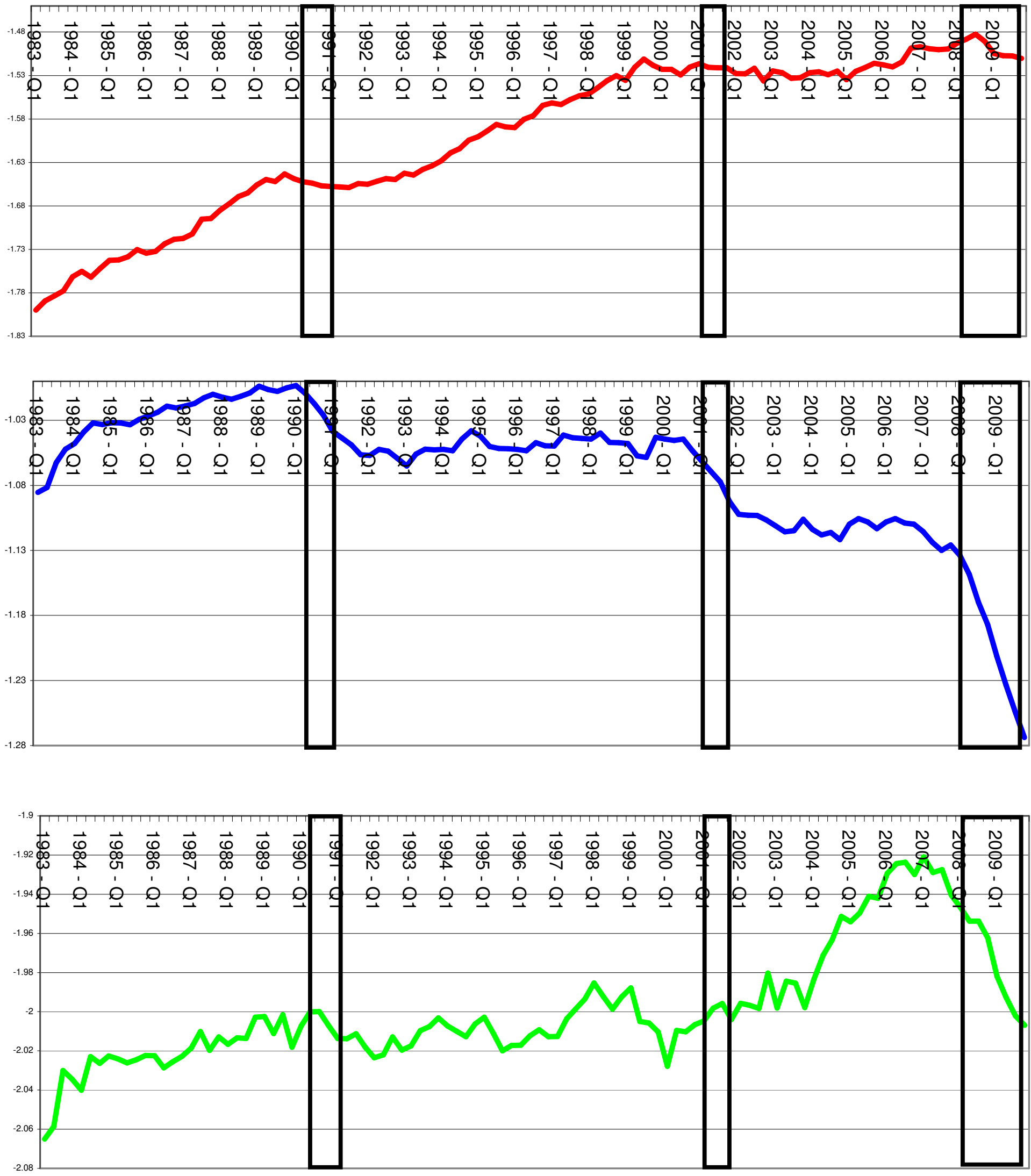

Note: Employment by each occupation group over total population (16 years and older). Expressed in logs. Red: High Skill; Blue: Middle Skill; Green: Low Skill. See data appendix for further details. 


\section{Figure 4-Neutral technology shock}
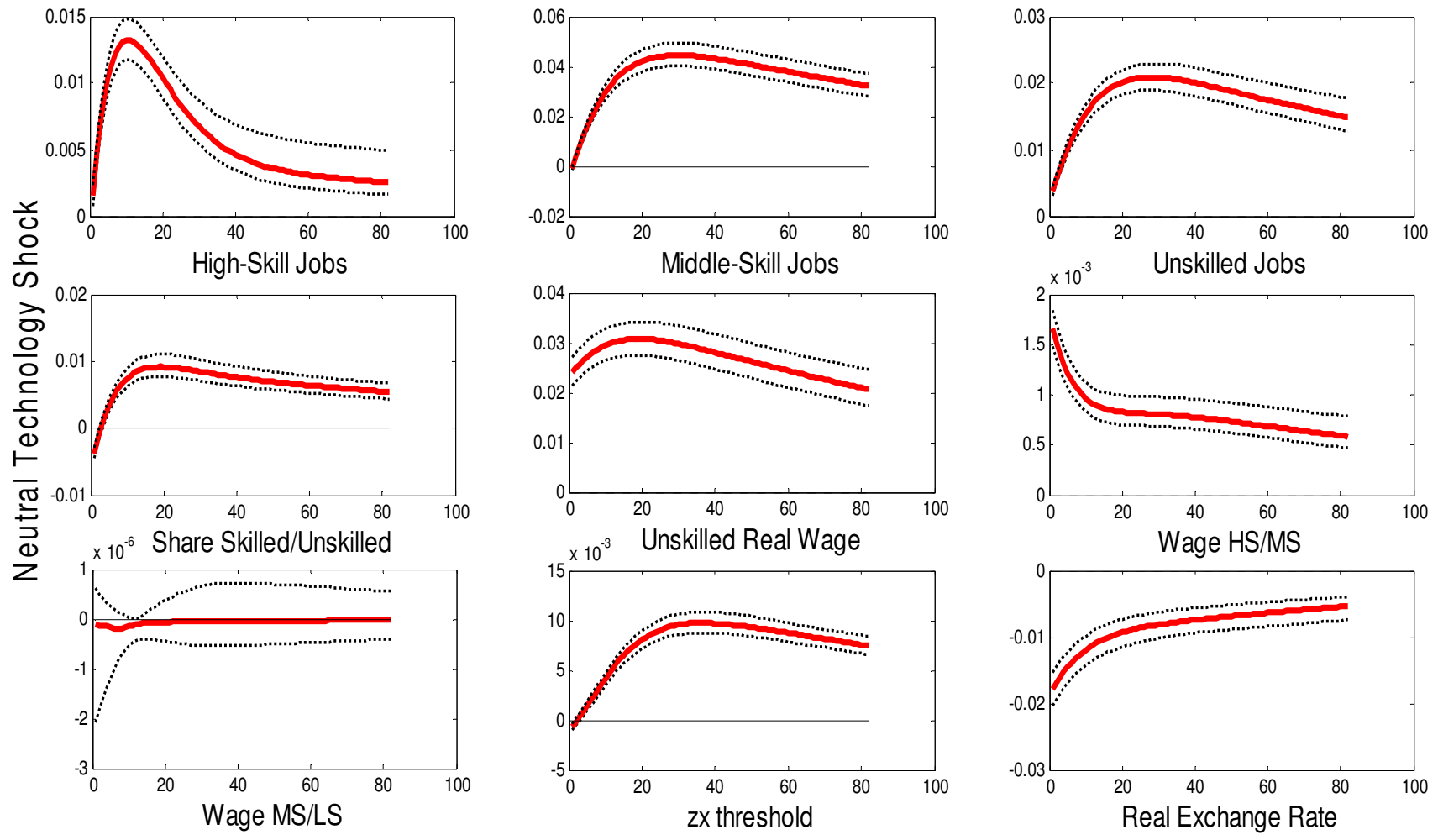

Note: The solid line is the median impulse response to one standard deviation of the estimated shock; the dotted lines are the 10 and 90 percent posterior intervals.

\section{Figure 5- Decline in trade costs}
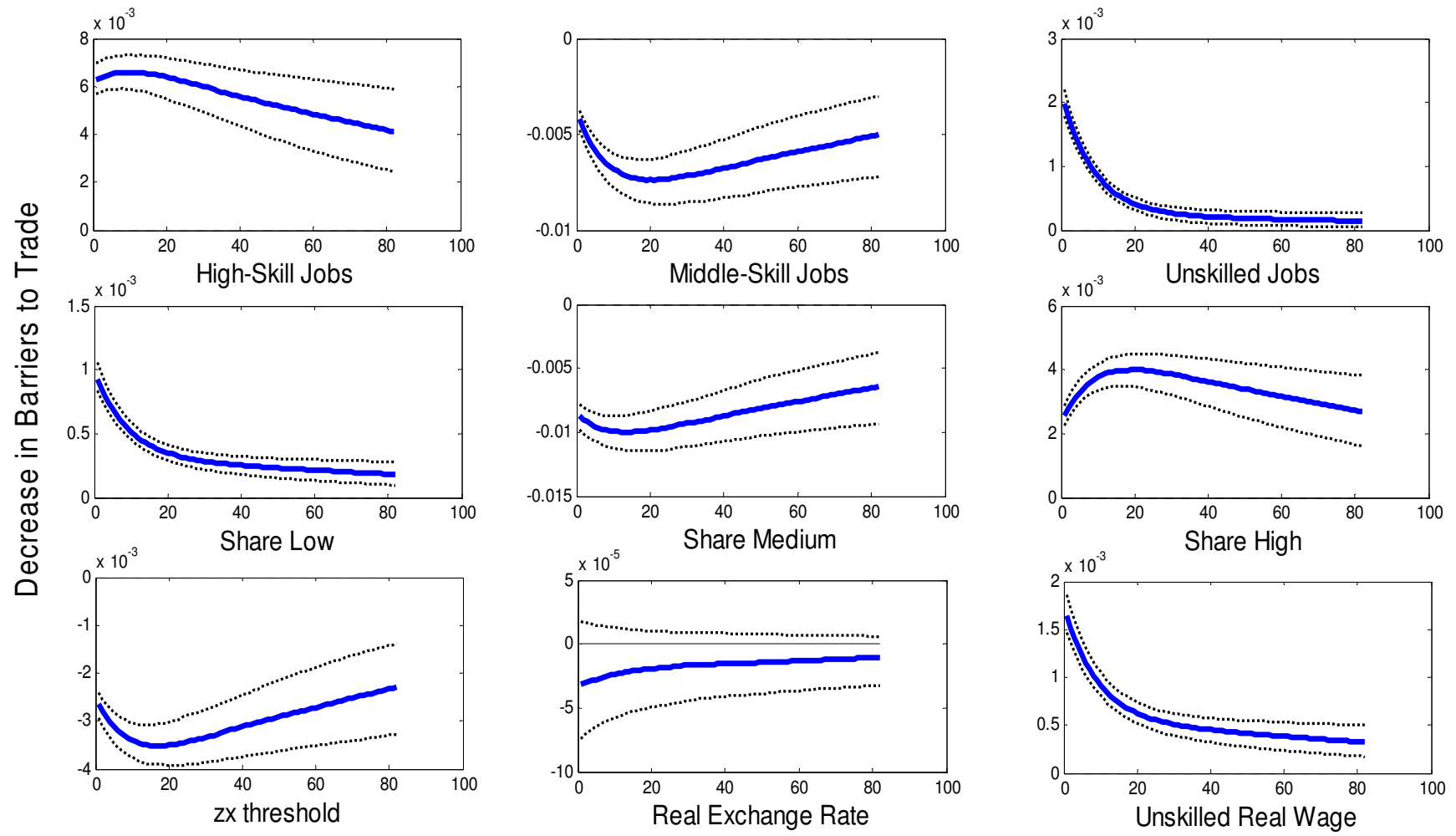

Note: Refer to Fig.5 for details. 
Figure 6- Asymmetric discount factor shock
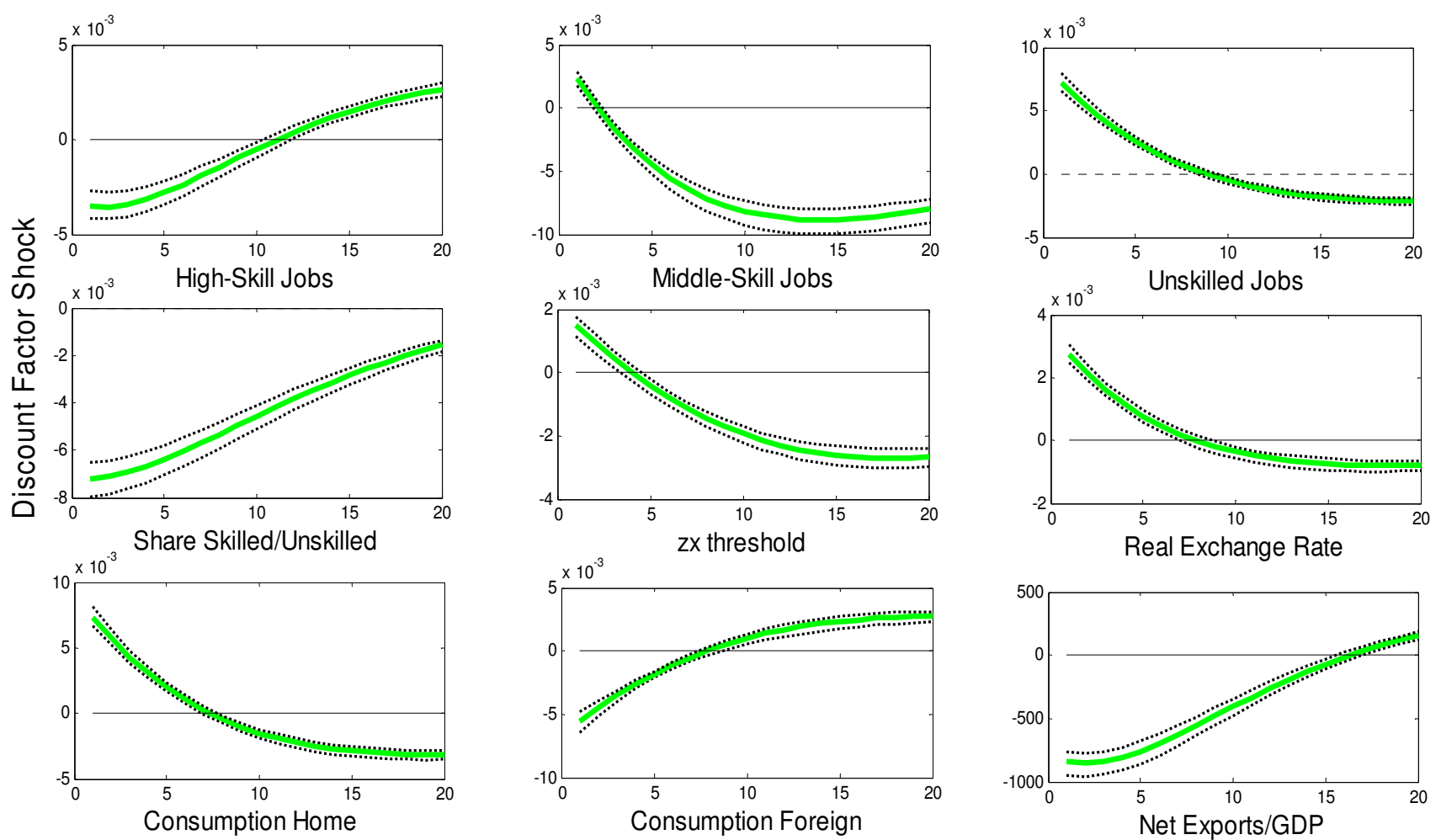

Note: Refer to Fig.5 for details. The calibration assumes balanced net exports (i.e. zero) at the balanced growth path. In the computations this number is instead negligible (due to approximation error). Therefore, the percentage deviations from this nil value appear to be large.

\section{Figure 7- Data and predicted values from the model}
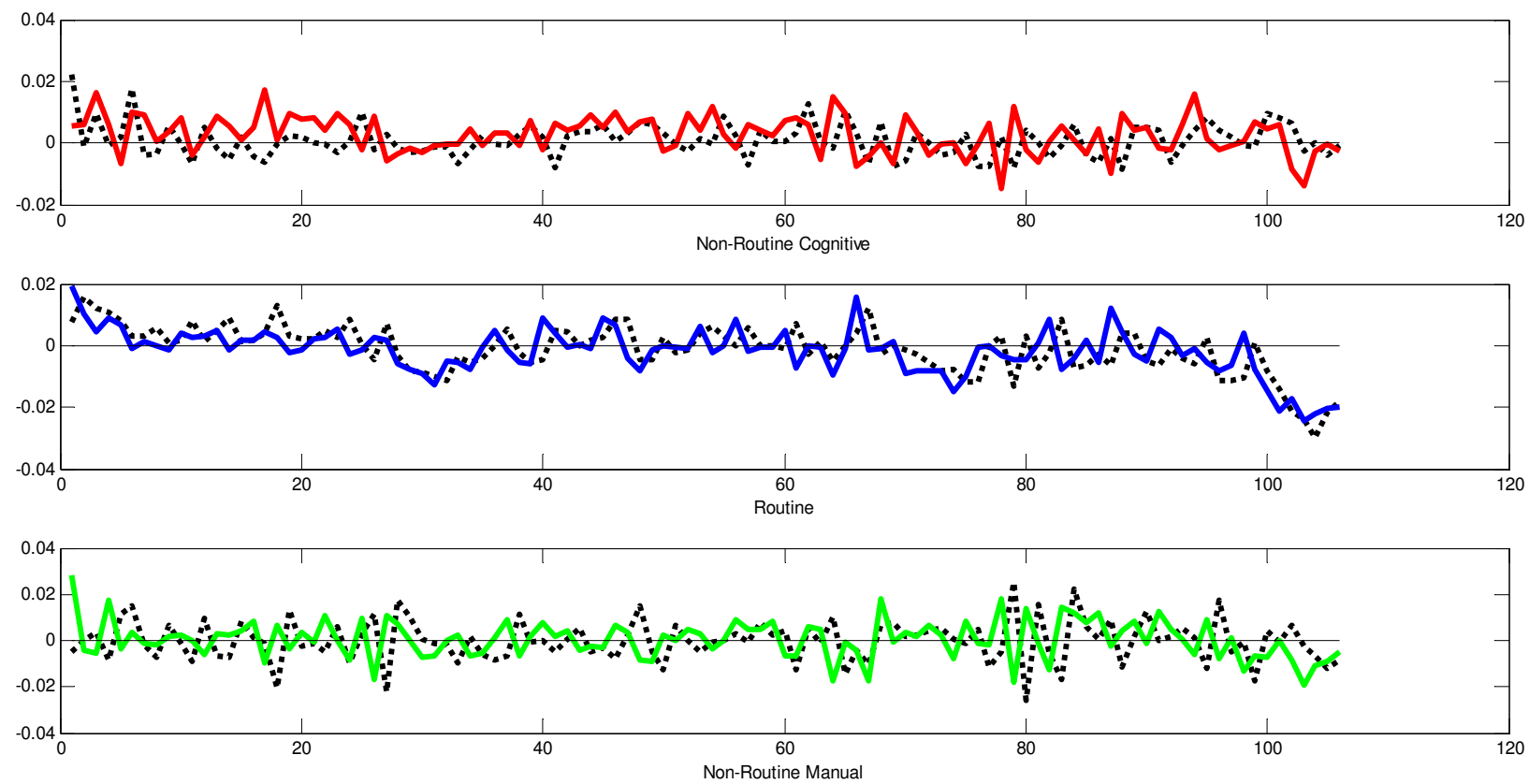

Note: Data (solid line) and benchmark model's Kalman filtered one-sided predicted values (dashed line). Variables are expressed in growth rates. 
Figure 8. Historical Decomposition (High-Skill; Middle-Skill; Low-Skill)

$$
\rightarrow \text { Trade } \longrightarrow \text { Demand } \longrightarrow \text { TOTAL } \leadsto \text { Technology }
$$
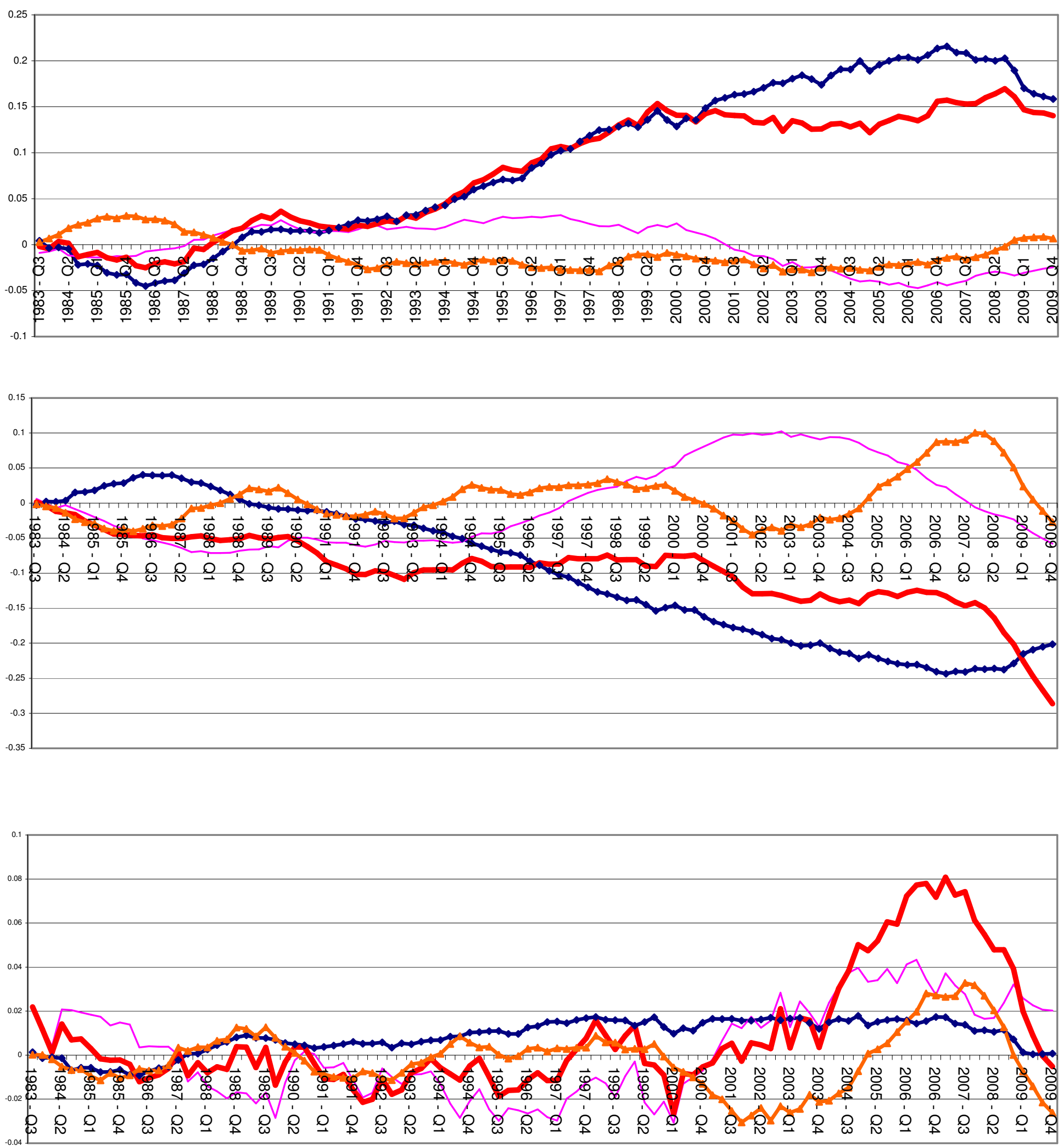

Note: Historical contribution of structural shocks (technology, trade costs, and discount factor) to different employment groups over the sample period. 


\section{Figure 9- Autocovariance functions}
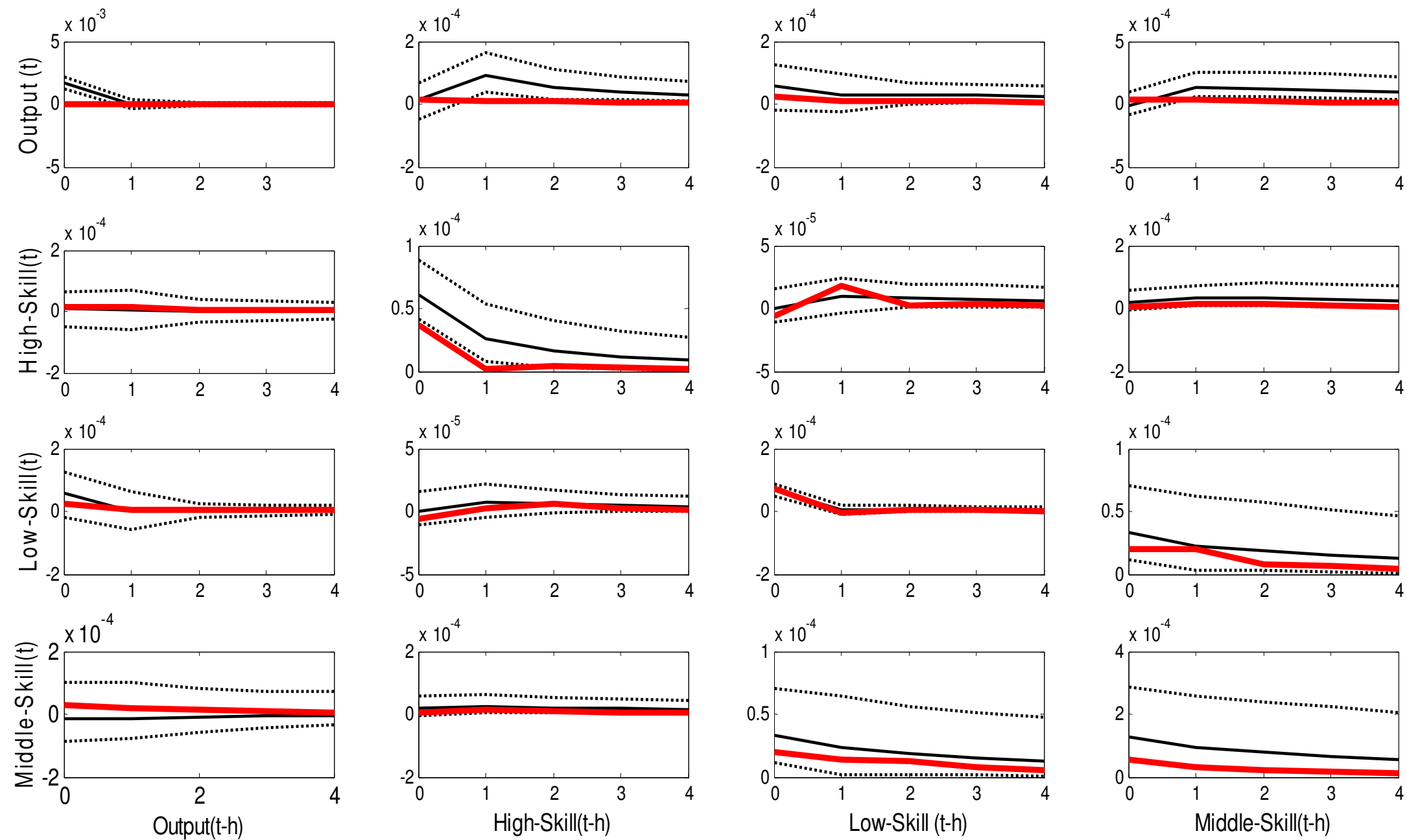

Note: The vector auto-covariance function is computed by estimating an unrestricted VAR (1) model with an uninformative prior for the variables plotted. The thin (solid) line refers to the median vector auto-covariance function along the 2.5 and 97.5 percentiles (dotted lines).The tick line refers to the actual data 
Figure A1- Investment-Specific Technology Shock-
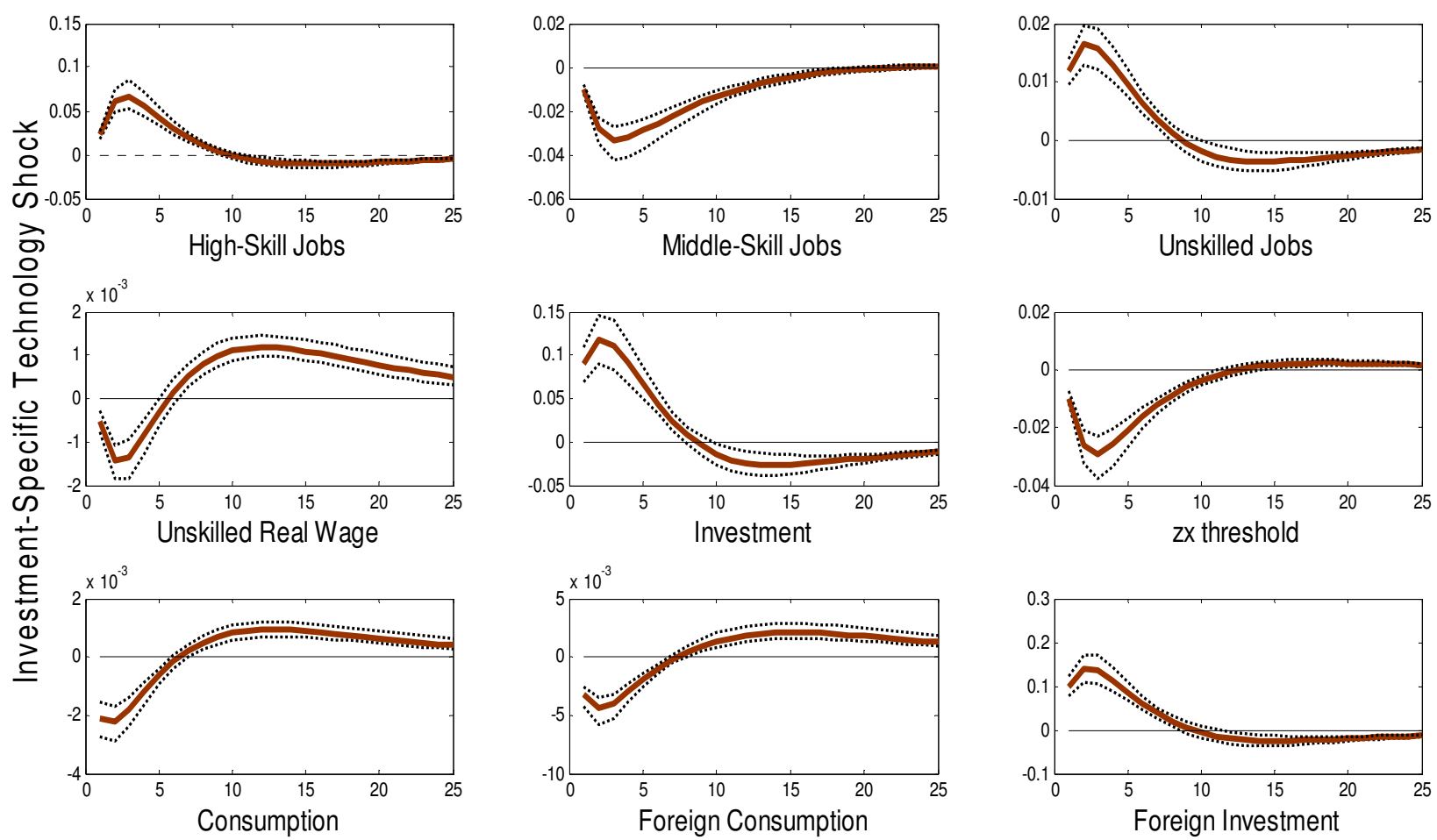

Note: Refer to Fig.5 for details.

Figure A2- Asymmetric countries: permanent effects on the balanced growth path
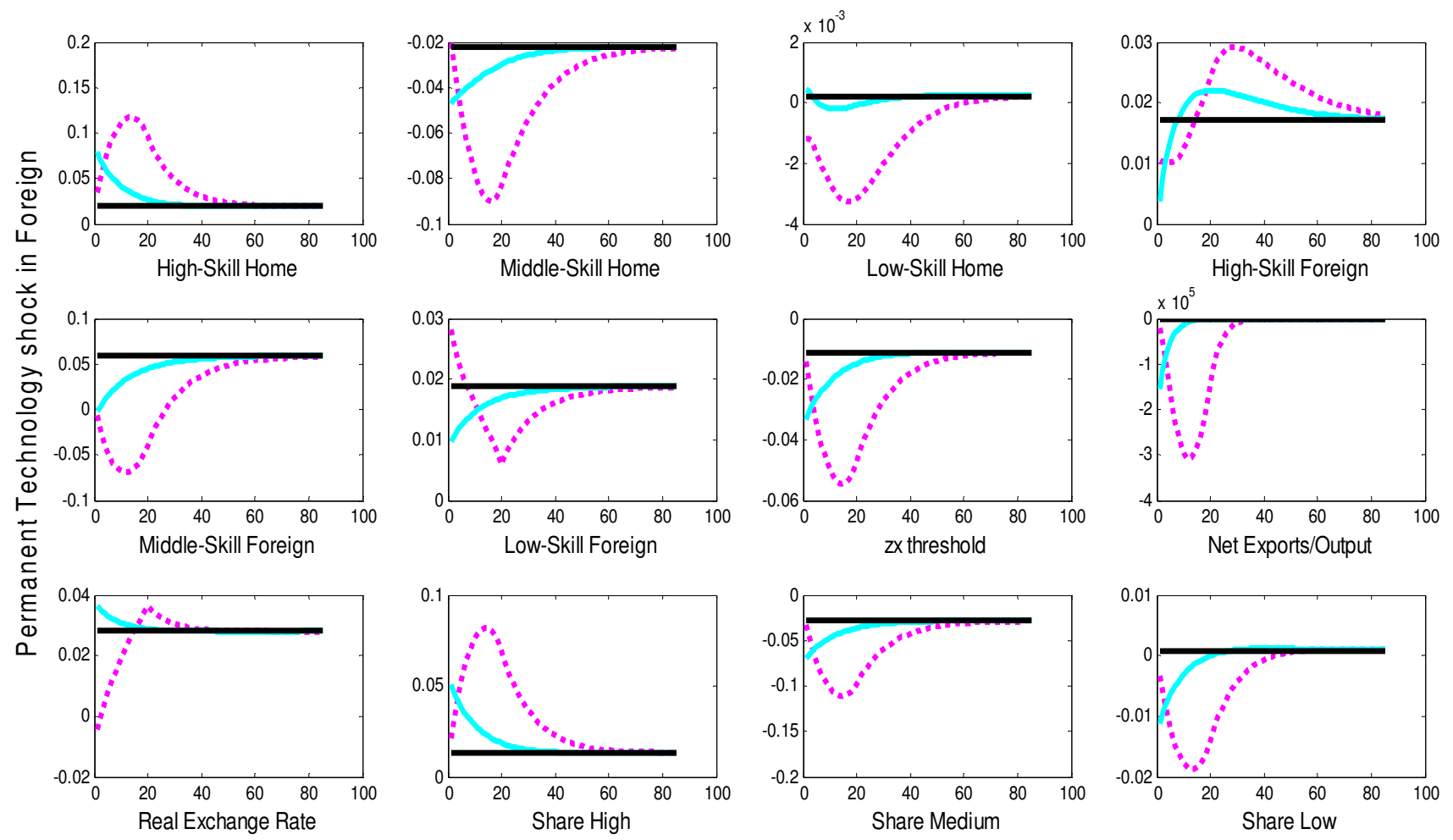

Note: Permanent increase in foreign technology over 5 years (20 quarters). This increase occurs at a decreasing rate until reaching a new balanced-growth path where TFP in Foreign is one percent higher than in the initial period. 


\title{
Labor Market Polarization and International Macroeconomic Dynamics
}

\section{TECHNICAL APPENDIX}

\author{
Federico S. Mandelman ${ }^{1}$
}

This section presents supplemental material and results. It includes: (1) The system equations characterizing the equilibrium conditions of the model, where real variables are re-scaled to account for the unit-root technology process that renders the model non-stationary. (2) Bayesian estimation: description of the data sources, the estimation methodology, the empirical evaluation of the model performance, and the Kalman smoothing procedure. (3) Additional estimation results: variance decomposition, plots of the prior and posterior densities of the parameters of the benchmark model, estimation results for the extended model with capital, and sensitivity analysis: the benchmark model is estimated with alternative stochastic processes. (4) Markov Chain Monte Carlo (MCMC) multivariate convergence diagnostics.

\section{Normalization of the Model}

Normalization of the Optimality Conditions for the model with capital The presence of a unit-root global technology shock makes the model non-stationary, so real variables are re-scaled. A hat indicates such normalization in the first-order conditions depicted below. For instance: $\hat{Y}_{t}=\frac{Y_{t}}{X_{t}}$. A similar normalization holds for the remaining real variables in Home and Foreign. Notice that employment and (real) prices are stationary. The focus is in Home, with analogous equations holding for Foreign. I denote foreign variables with an asterisk.

\footnotetext{
${ }^{1}$ Beyond the usual disclaimer, I must note that any views in this paper are solely the responsibility of the author and should not be interpreted as reflecting the views of the Federal Reserve Bank of Atlanta or the Federal Reserve System.
} 
Relative Wages:

$$
\begin{aligned}
& \tilde{w}_{D, t}=w_{D, t}\left(\tilde{\mathbf{z}}_{D, t}, .\right)=\frac{\theta}{\theta-1} \frac{\hat{w}_{\mathbf{u}, t}}{\varepsilon_{t}^{Z} v}, \text { where } v=\{k /[k-(\theta-1)]\}^{\frac{1}{(\theta-1)}} \\
& \tilde{w}_{X, t}=w_{X, t}\left(\tilde{\mathbf{z}}_{X, t} . .\right)=\tau \varepsilon_{t}^{\tau} \frac{1}{Q_{t}} \frac{\theta}{\theta-1} \frac{\hat{w}_{\mathbf{u}, t}}{\varepsilon_{t}^{Z} \tilde{\mathbf{z}}_{X, t}}
\end{aligned}
$$

Skill income premia:

$$
\begin{aligned}
\hat{\pi}_{D, t} & =\hat{\pi}_{D, t}\left(\tilde{\mathbf{z}}_{D, t} . .\right)=\frac{1}{\theta}\left(\tilde{w}_{D, t}\right)^{1-\theta} \hat{\mathbb{N}}_{t} . \\
\hat{\pi}_{X, t} & =\hat{\pi}_{X, t}\left(\tilde{\mathbf{z}}_{X, t} . .\right)=\frac{\mathbb{Q}_{t}}{\theta}\left(\tilde{w}_{X, t}\right)^{1-\theta} \hat{\mathbb{N}}_{t}^{*}-\hat{f}_{o, t}, \text { where } \hat{f}_{o, t}=\frac{\hat{w}_{\mathbf{u}, t} f_{o}}{\varepsilon_{t}^{Z}} \\
\hat{\pi}_{t} & =\left(N_{D, t} \hat{\pi}_{D, t}+N_{X, t} \hat{\pi}_{X, t}\right) / N_{D, t}
\end{aligned}
$$

Wage Bill:

$$
\mathbb{W}_{t}=\left[N_{D, t}\left(\tilde{w}_{D, t}\right)^{1-\theta}+N_{X, t}^{*}\left(\tilde{w}_{X, t}^{*}\right)^{1-\theta}\right]^{\frac{1}{1-\theta}}
$$

Training Decision:

$$
\begin{array}{r}
\hat{f}_{e, t}=\beta(1-\delta) \mathbb{E}_{t}\left[\frac{\hat{\zeta}_{t+1}}{\hat{\zeta}_{t}}\left(\hat{f}_{e, t+1}+\hat{\pi}_{t+1}\right)\left(\frac{X_{t+1}}{X_{t}}\right)^{1-\gamma}\right], \\
\text { with } \hat{\zeta}_{t}=\frac{\varepsilon_{t}^{b}\left(\hat{C}_{t}\right)^{\gamma}}{P_{t}} ; \text { where } \hat{\zeta}_{t}=\zeta_{t}\left(X_{t}\right)^{\gamma}, \hat{f}_{e, t}=\frac{\hat{w}_{\mathbf{u}, t} f_{e}}{\varepsilon_{t}^{Z}}
\end{array}
$$

\section{Outsourcing Cutoffs:}




$$
\begin{aligned}
\frac{N_{X, t}}{N_{D, t}} & =\left(\frac{v}{\tilde{\mathbf{z}}_{X, t}}\right)^{k} \\
\hat{\pi}_{X, t} & =\hat{f}_{o, t} \frac{\theta-1}{k-(\theta-1)}
\end{aligned}
$$

Job Turnover:

$$
N_{D, t}=(1-\delta)\left(N_{D, t-1}+N_{E, t-1}\right)
$$

Leisure Optimality:

$$
a_{n} X_{t}^{\gamma-1}\left(L_{t}\right)^{\gamma_{n}}\left(\hat{C}_{t}\right)^{\gamma}=\frac{\hat{w}_{\mathbf{u}, t}}{P_{t}}
$$

\section{UIP Condition:}

$$
\mathbb{E}_{t}\left\{\frac{\hat{\zeta}_{t+1}^{*}}{\hat{\zeta}_{t}^{*}}\left(\frac{X_{t+1}}{X_{t}}\right)^{-\gamma} \frac{Q_{t}}{\mathbb{Q}_{t+1}}\right\}=\mathbb{E}_{t}\left\{\frac{\hat{\zeta}_{t+1}}{\hat{\zeta}_{t}}\left(\frac{X_{t+1}}{X_{t}}\right)^{-\gamma}\right\}-\phi \frac{\hat{B}_{t}}{\beta}
$$

Aggregate Accounting/Current Account:

$$
\begin{aligned}
& q_{t} \hat{B}_{t}=\left(\frac{X_{t-1}}{X_{t}}\right) \hat{B}_{t-1}+\hat{w}_{\mathbf{u}, t} L_{t}+N_{D, t} \hat{\pi}_{t}+\left(1+r_{t}^{k}\right)\left(\frac{X_{t-1}}{X_{t}}\right) \hat{K}_{t-1}-P_{t} \hat{C}_{t}-P_{t} \hat{I}_{t}-\hat{f}_{e, t} N_{e, t}-\frac{\phi}{2} \hat{B}_{t} \\
& q_{t} \hat{B}_{t}=\left(\frac{X_{t-1}}{X_{t}}\right) \hat{B}_{t-1}+\mathbb{Q}_{t} N_{X, t}\left(\tilde{w}_{X, t}\right)^{1-\theta} \hat{\mathbb{N}}_{t}^{*}-N_{X, t}^{*}\left(\tilde{w}_{X, t}^{*}\right)^{1-\theta} \hat{\mathbb{N}}_{t}-\frac{\phi}{2} \hat{B}_{t}
\end{aligned}
$$

\section{Capital Accumulation:}

$$
\hat{K}_{t}=\left(1-\delta^{k}\right) \hat{K}_{t-1}\left(\frac{X_{t-1}}{X_{t}}\right)+\varepsilon_{t}^{V} \hat{I}_{t}-\frac{\phi^{k}}{2} \hat{I}_{t-1}\left(\frac{X_{t-1}}{X_{t}}\right) \varepsilon_{t-1}^{V}\left[\left(\frac{X_{t}}{X_{t-1}}\right) \frac{\hat{I}_{t} \varepsilon_{t}^{V}}{\hat{I}_{t-1} \varepsilon_{t-1}^{V}}-\Lambda_{X}\right]^{2}
$$

Euler Equation for Capital: 


$$
P_{t} \hat{\zeta}_{t}=\hat{\lambda}_{t} \varepsilon_{t}^{V}\left(1-\phi^{k} \hat{\Omega}_{t}\right)+\beta \mathbb{E}_{t}\left\{\hat{\lambda}_{t+1}\left(\frac{X_{t}}{X_{t+1}}\right)^{\gamma} \varepsilon_{t+1}^{V}\left[\phi^{k} \hat{\Omega}_{t+1} \frac{\hat{I}_{t+1}}{\hat{I}_{t}}\left(\frac{X_{t+1}}{X_{t}}\right)-\frac{\phi^{k}}{2} \frac{\varepsilon_{t}^{V}}{\varepsilon_{t+1}^{V}}\left(\hat{\Omega}_{t+1}\right)^{2}\right]\right\}
$$

where $\hat{\lambda}_{t}=\lambda_{t}\left(X_{t}\right)^{\gamma}$, and $\hat{\Omega}_{t}=\left(\frac{X_{t}}{X_{t-1}}\right) \frac{I_{t} \varepsilon_{t}^{V}}{I_{t-1} \varepsilon_{t-1}^{V}}-\Lambda_{X}$

$$
\hat{\lambda}_{t}=\beta \mathbb{E}_{t}\left\{\left(1+r_{t+1}^{k}\right)\left(\frac{X_{t}}{X_{t+1}}\right)^{\gamma} \hat{\zeta}_{t+1}+\hat{\lambda}_{t+1}\left(\frac{X_{t}}{X_{t+1}}\right)^{\gamma}(1-\delta)\right\}
$$

Production/Factor Demand:

$$
\begin{gathered}
\hat{Y}_{t}^{T}=\left\{\alpha\left[\hat{K}_{t-1}\left(\frac{X_{t-1}}{X_{t}}\right)\right]^{\frac{\sigma-1}{\sigma}}+(1-\alpha) \hat{\mathbb{N}}_{t}\right\}^{\frac{\sigma}{\sigma-1}} \\
(1-\alpha)\left(\frac{\hat{Y}_{t}^{T}}{\hat{\mathbb{N}}_{t}}\right)^{\frac{1}{\sigma}}=\frac{1}{P_{t}^{T}}, \alpha\left(\frac{\hat{Y}_{t}^{T}}{\hat{K}_{t-1}}\left(\frac{X_{t}}{X_{t-1}}\right)\right)^{\frac{1}{\sigma}}=\frac{\left(1+r_{t}^{k}\right)}{P_{t}^{T}} \\
\hat{Y}_{t}^{N}=\hat{L}_{N, t}, P_{t}^{N}=\hat{w}_{\mathbf{u}, t} \\
\hat{C}_{t}+\hat{I}_{t}=\left[\left(\gamma_{c}\right)^{\frac{1}{\rho_{c}}}\left(\hat{Y}_{T, t}\right)^{\frac{\rho_{c-1}}{\rho_{c}}}+\left(1-\gamma_{c}\right)^{\frac{1}{\rho_{c}}}\left(\hat{Y}_{N, t}\right)^{\frac{\rho_{c-1}}{\rho_{c}}}\right]^{\frac{\rho_{c}}{\rho_{c}-1}} \\
P_{t}=\left[\left(\gamma_{c}\right)^{\left.\left(P_{T, t}\right)^{1-\rho_{c}}+\left(1-\gamma_{c}\right)\left(P_{N, t}\right)^{1-\rho_{c}}\right] .}\right.
\end{gathered}
$$

Normalization of the model without capital The baseline model without capital is a simplified version of the model above. The following differences emerge. First, Equations (A15), (A16), (A17) are no longer part of the system in the baseline specification. Equations (A18) and (A19) become $\hat{Y}_{t}^{T}=\hat{\mathbb{N}}_{t}$; and $P_{t}^{T}=\mathbb{W}_{t} \equiv 1$, respectively. The expression, $\hat{I}_{t}$, disappears from the LHS of equation (A21) while $\left(1+r_{t}^{k}\right)\left(\frac{X_{t-1}}{X_{t}}\right) \hat{K}_{t-1}$ and $P_{t} \hat{I}_{t}$ must be removed from the right hand side of (A13). In both specifications, 
$\mathbb{W}_{t} \equiv 1$, serves as the numeraire.

Auxiliary equations for the baseline specification The income share for the high-skill group is:

$$
S_{h}^{H}=\frac{N_{X, t}\left(\pi_{D, t}\left(\tilde{\mathbf{z}}_{X, t} . .\right)+\pi_{X, t}\left(\tilde{\mathbf{z}}_{X, t} . .\right)\right)+w_{\mathbf{u}, t} L_{t}^{\tilde{\mathbf{z}}_{X, t}}}{Y_{t}^{\mathbb{W}}}
$$

where $\pi_{D, t}\left(\tilde{\mathbf{z}}_{X, t},.\right)=\frac{1}{\theta}\left(\frac{\theta}{\theta-1} \frac{w_{\mathbf{u}, t}}{\varepsilon_{t}^{Z} \tilde{\mathbf{z}}_{X, t}}\right)^{1-\theta} \mathbb{N}_{t}$ is the labor income premium for the tasks that are suitable to be outsourced (i.e. with productivity above the threshold value $\mathbf{z}_{X, t}$ ) when executed domestically; $L_{t}^{\tilde{\mathbf{z}}_{X, t}}=$ $N_{X, t}\left[\frac{(\theta-1)}{w_{\mathbf{u}, t}}\left(\pi_{D, t}\left(\tilde{\mathbf{z}}_{X, t},.\right)+\pi_{X, t}\left(\tilde{\mathbf{z}}_{X, t},.\right)\right)+\theta f_{o} / \varepsilon_{t}^{Z}\right]$ is the total units of raw labor embodied in all tasks situated above this threshold value. Finally, $Y_{t}^{\mathbb{W}}=P_{t} Y_{t}-f_{e, t} N_{e, t}$ is the income-based GDP net of training costs, which are not used in production (expressed in terms of the numeraire). The income share for the low-skill labor input in services is $S_{h}^{L}=w_{\mathbf{u}, t} L_{N, t} / Y_{t}^{\mathbb{W}}$. Consequently, the remaining share for the middleskill continuum, $N_{M, t}$, is $S_{h}^{M}=1-S_{h}^{H}-S_{h}^{H}$.

When labor is the only production factor possible, it is a straightforward process to obtain the associated wage skill premium for each skill group. The premium for the high-skill group, $N_{X, t}$, with respect to the middle, $N_{M, t}$, is: $\frac{\left(S_{h}^{H} Y_{t}^{\mathbb{W}}\right) / L_{t}^{\tilde{z}_{X, t}}}{\left(S_{h}^{M} Y_{t}^{\mathbb{W}}\right) / L_{t}^{\tilde{z}_{M, t}}}$, where $L_{t}^{\tilde{\mathbf{z}}_{M, t}}=L_{t}-L_{t}^{\tilde{\mathbf{z}}_{X, t}}-L_{N, t}-N_{e, t} f_{e} / \varepsilon_{t}^{Z}$. Similarly, the premium for the latter group with respect to the low-skill group is: $\frac{\left(S_{h}^{M} Y_{t}^{W}\right) / L_{t}^{\tilde{z}_{M, t}}}{w_{\mathbf{u}, t}}$.

\section{Bayesian Estimation}

Data Sources In the main text, Fig. 1 is constructed following the methodology used in Autor and Dorn (2012). The American Community Survey (which includes 1\% of the population) and the IPUMS census data (5\% of the population) for the years 2010 and 1980, respectively are used. Occupations are sorted into 100 percentiles based on the mean occupational wages and the relative importance of occupations in $1980 .^{2}$ The employment shares are computed for each occupation and then are aggregated at the percentile level. The change in shares is obtained as the simple difference between the share of em-

\footnotetext{
${ }^{2}$ As discussed in Acemoglu and Autor (2011), the ordering does not change significantly if a diffferent base year is used.
} 
ployment in 2010 and 1980 for each percentile. The smooth changes plotted in the figure are obtained using a locally-weighted polynomial regression between the change in employment and the corresponding percentile. In Panel B, the counterfactual changes on employment are calculated assuming that all services remain at the level of 1980. Mimicking the methodological approach in Autor and Dorn (2012), this counterfactual is constructed by pooling ACS data from 2010 with census data from 1980. This approach consists of estimating a weighted logit model for the odds, from which an observation is drawn from the 1980 census sample (relative to the actual sampling year), using as predictors a service occupation dummy and an intercept. Weights used are the product of census sampling weights and annual hours of labor supply. Observations in 2010 are reweighted using the estimated odds multiplied by the hours-weighted census sampling weight, weighting downward the frequency of service occupations in 2010 to their 1980 level. Given the absence of other covariates in the model, the extra probability mass is implicitly allocated uniformly over the remainder of the distribution.

U.S. Real GDP, personal consumption expenditures, real net exports, and investment data come from the U.S. Bureau of Economic Analysis. Real Foreign GDP is a weighted average from Haver Analytics. ${ }^{3}$ Similarly, the real exchange rate is the trade-weighted indicator constructed by the Board of Governors of the Federal Reserve System.

The population measure is the civilian non-institutional population, 16 years and older, and is taken from the Current Population Survey (CPS), Bureau of Labor Statistics. This database is retrieved from the FRED database, Federal Reserve Bank of St. Louis. Aggregate employment is total employment within this population. Data on employment at the occupation group level is from the same source. The classification is based on the categorization of occupations in the 2000 Standard Occupational classification system, which closely follows the approach in Jaimovich and Siu (2012). ${ }^{4}$ Non-routine cognitive workers are in "management, business, and financial operations occupations" and "professional and related occu-

\footnotetext{
${ }^{3}$ The countries included are Canada, Germany, France, Italy,Netherlands, Belgium, Spain, Ireland, Austria, Finland, Portugal, Greece, Japan, Mexico, China, UK, Taiwan, Korea, Singapore, Hong Kong, Malaysia, Brazil, Switzerland, Thailand, Australia, Indonesia, Philippines, Russia, India, Sweden, Saudi Arabia, Israel, Argentina, Venezuela, Chile, and Colombia.

4Jaimovich and Siu (2012) show that their group classification is robust to the analysis in Autor and Dorn (2012) which provides a more comprehensive definition with six categories based on an occupation's degree of intensity in abstract, routine and manual tasks, respectively.
} 
pations." Routine cognitive workers are those in "sales and related occupations" and "office and administrative support occupations." Routine manual occupations are "production occupations", "transportation and material moving occupations," and "installation, maintenance, and repair occupations." Non-routine manual occupations are "service occupations" and "construction and extraction occupations." All of the data is seasonally adjusted with the X-12 ARIMA method from the U.S. Census Bureau. As explained in Jaimovich and Siu (2012) and Firpo et al (2011), this group classification corresponds to rankings in the occupational income distribution: non-routine cognitive occupations tend to be high-skill occupations whereas non-routine manual occupations tend to be low-skill. Routine occupations both cognitive and manual are middle-skill occupations. The categorization of occupations in my paper is slightly different than that in Jaimovich and Siu (2012). Namely, construction occupations are grouped among those providing low-skill/non-tradable tasks. I take this approach for two reasons. First, construction jobs are intrinsically non-tradable and thus not subject to offshorability. Second, even though the average hourly earnings of construction workers belong to the middle (and not the bottom) of earnings distributions in CPS classification, some important caveats exist. For example, the underground economy is particularly pervasive in this sector. Construction is densely populated by low-skill laborers who execute non-routine manual tasks that hardly can be mechanized. Many contractors are unregistered workers, and many of the registered ones subcontract by hiring hourly low-wage laborers without keeping records. ${ }^{5}$ Despite this fact, the models' results are similar when I include construction occupations within the middle-skill segment.

Estimation Methodology In this section, I briefly explain the estimation approach used in this paper. A more detailed description of the method can be found in Rubio-Ramirez and Fernandez-Villaverde (2004) and Justiniano and Preston (2010), among others. Let's define $\Theta$ as the parameter space of the DSGE model, and $z^{T}=\left\{z_{t}\right\}_{t=1}^{T}$ as the data series used in the estimation. Their joint probability distri-

\footnotetext{
${ }^{5}$ For instance, a FPI report (2007) shows that despite the residential construction boom of the early 2000s in the New York City metropolitan area in which construction permits more than doubled, there was negligible increase in the official count of the New York City residential construction workers (which contradicts the evidence). In a related paper, Hotchkiss and Quispe-Agnoli (2012) find that the construction industry is, proportionally, the largest employer of undocumented immigrants.
} 
bution, $P\left(z^{T}, \Theta\right)$, results in a relationship between the marginal, $P(\Theta)$, and the conditional distribution $P\left(z^{T} \mid \Theta\right)$, which is known as the Bayes theorem: $P\left(\Theta \mid z^{T}\right) \propto P\left(z^{T} \mid \Theta\right) P(\Theta)$. The method updates the $a$ priori distribution using the likelihood to obtain the conditional posterior distribution of the structural parameters in the data. The resulting posterior density $P\left(\Theta \mid z^{T}\right)$, is used to draw statistical inference on the parameter space, $\Theta$. Combining the state-form representation implied by the solution for the linear rational expectation model and the Kalman filter, I can compute the likelihood function. The likelihood and the prior permit a computation of the posterior that can be the starting value of the random walk version of the Metropolis-Hastings $(\mathrm{MH})$ algorithm, which is a Monte Carlo method that generates draws from the posterior distribution of the parameters. In this case, the results reported are based on 100,000 draws from this algorithm. I choose a normal jump distribution with covariance matrix equal to the Hessian of the posterior density evaluated at the maximum. The scale factor is chosen to deliver an acceptance rate between $35 \%$ and $50 \%$ depending on the run of the algorithm. Measures of uncertainty follow from the percentiles of the draws.

Bayesian Model Comparison The marginal likelihood follows: $M_{A}=\int_{\Theta} P(\Theta \mid A) P\left(z^{T} \mid \Theta, A\right) d \Theta$, where $P(\Theta \mid A)$ is the prior density for model $A, M_{A}$, and $P\left(z^{T} \mid \Theta, A\right)$ is the likelihood function of the observable data, conditional on the parameter space, $\Theta$, and the model, $A$. The marginal likelihood of a model is directly related to the predicted density of the model given by: $\hat{p}_{T+1}^{T+m}=\int_{\Theta} P\left(\Theta \mid z^{T}, A\right) \prod_{t=T+1}^{T+m} P\left(z_{t} \mid z^{T}, \Theta, A\right) d \Theta$, where $\hat{p}_{0}^{T}=M_{T}$. Therefore the marginal likelihood of a model also reflects its prediction performance.The Bayes factor between two models $A$ and $B$ is defined as: $\mathcal{F}_{A B}=M_{A} / M_{B}$ and serves as the method of model selection. Since $\ln \left(\mathcal{F}_{A B}\right)=\log \left(M_{A} / M_{B}\right)=\log \left(M_{A}\right)-\log \left(M_{B}\right)$, we can interpret the Bayes factor as the difference of the log marginal likelihood of each specification.

Smoothing The DSGE model can be written in a state-space representation as $\xi_{t+1}=F \xi_{t}+v_{t+1}$ and $z_{t}=H^{\prime} \xi_{t}+w_{t}$, in which $\xi_{t}$ is the vector of unobserved variables at date $t$, and $z_{t}$ is the vector of observables; shocks $v_{t}$ and $w_{t}$ are uncorrelated, normally distributed, white noise vectors. The first 
expression is the state equation, and the second is the observed equation.

Smoothing involves the estimation of $\xi^{T}=\left\{\xi_{t}\right\}_{t=1}^{T}$, conditional on the full data set, $z^{T}$, used in the estimation. The smoothed estimates are denoted as $\xi_{t \mid T}=E\left(\xi_{t} \mid z^{T}\right)$ and, as shown in Bauer et al. (2003), can be written as:

$$
\xi_{t \mid T}=\xi_{t \mid t}+P_{t \mid t} F^{\prime} P_{t+1 \mid t}^{-1}\left[\xi_{t+1 \mid T}-\xi_{t+1 \mid t}\right]
$$

in which $P_{t+1 \mid t}=E\left(\xi_{t+1}-\xi_{t+1 \mid t}\right)\left(\xi_{t+1}-\xi_{t+1 \mid t}\right)^{\prime}$ is the mean squared forecasting error associated with the projection of $\xi_{t+1}$ on $z^{t}$ and a constant, projection which is denoted as $\xi_{t+1 \mid t}=E\left(\xi_{t+1} \mid z^{t}\right)$. Using

the Kalman filter to calculate, $\left\{\xi_{t}\right\}_{t=1}^{T},\left\{\xi_{t+1 \mid t}\right\}_{t=0}^{T-1},\left\{P_{t \mid t}\right\}_{t=1}^{T}$, and $\left\{P_{t+1 \mid t}\right\}_{t=0}^{T-1}$, the sequence of smooth estimates, $\left\{\xi_{t \mid T}\right\}_{t=1}^{T}$, is determined from equation (1).

\section{Additional Estimation Results}

Variance Decomposition Fig. TA1 displays the forecast error variance decomposition of key economic variables (foreign output, domestic consumption, and employment for each skill group) at various quarterly horizons (Q1, Q4, Q16, and Q40), based on the posterior benchmark estimation. As discussed, the model identifies shocks affecting the trade costs (cross-country symmetric ice-melting), technology (temporary and permanent), and consumption demand (asymmetric intertemporal rate of substitution).

In the model, skilled employment in the tradable sector is rendered as a state variable by the sunk training cost. Thus the estimated shocks have a negligible impact at very short horizons. Instead, innovations to trading costs appear to have a sizable effect on the margin of offshoring. Similarly, the demand for services (and its low-skill employment) react on impact to the aggregate shocks. In this case, demand shocks affecting household consumption are the main factor driving the sectoral employment dynamics. The influence of aggregate disturbances of trade costs and consumption demand on employment tend to decline over time. Instead, productivity innovations in the domestic tradable sectors of each country become increasingly important over time. Foreign productivity shocks are most important at medium 
horizons.

As explained in the technical appendix, unit-root world technology shocks fail to affect employment per-capita given its stationary nature. However, they do play an important role in driving the dynamics of output and household consumption. Consistent with the permanent income hypothesis, these unitroot shocks explain most of the volatility of consumption on all horizons. The variability of Home and Foreign output is largely split between the global shock and the country-specific shocks, respectively affecting each country.

Figure TA2 shows the prior (grey line) and posterior density (black line) for the benchmark model.

\section{Convergence diagnostics}

I monitor the convergence of iterative simulations with the multivariate diagnostic methods described in Brooks and Gelman (1998). The empirical 80\% interval for any given parameter, $\varrho$, is taken from each individual chain first. The interval is described by the $10 \%$ and $90 \%$ of the $n$ simulated draws. In this multivariate approach, I define $\varrho$ as a vector parameter based upon observations, $\varrho_{j t}^{(i)}$, denoting the $i_{t h}$ element of the parameter vector in chain $j$ at time $t$. The direct analogue of the univariate approach in higher dimensions is to estimate the posterior variance-covariance matrix as: $\hat{V}=\frac{n-1}{n} W+\left(1+\frac{1}{m}\right) B / n$, where $W=\frac{1}{m(n-1)} \sum_{j=1}^{m} \sum_{t=1}^{n}\left(\varrho_{j t}-\bar{\varrho}_{j}.\right)\left(\varrho_{j t}-\bar{\varrho}_{j}\right)^{\prime}$ and $B / n=\frac{1}{m-1} \sum_{j=1}^{m}\left(\bar{\varrho}_{j .}-\bar{\varrho}_{. .}\right)\left(\bar{\varrho}_{j .}-\bar{\varrho}_{. .}\right)^{\prime}$. It is possible to summarize the distance between $\hat{V}$ and $W$ with a scalar measure that should approach 1 (from above) as convergence is achieved, given suitably overdispersed starting points. I can monitor both $\hat{V}$ and $W$, determining convergence when any rotationally invariant distance measure between the two matrices indicates that they are sufficiently close. Figure TA3 reports measures of this aggregate. ${ }^{6}$ Convergence is achieved before 100,000 iterations. General univariate diagnostics are not displayed, but they are available on request.

\footnotetext{
${ }^{6}$ Note that, for instance, the interval-based diagnostic in the univariate case becomes now a comparison of volumes of total and within-chain convex hulls. Brooks and Gelman (1998) propose to calculate for each chain the volume within $80 \%$, say, of the points in the sample and compare the mean of these with the volume from $80 \%$ of the observations from all samples together.
} 


\section{References}

[1] Brooks, Stephen and Andrew Gelman. 1998. General Methods for Monitoring Convergence of Iterative Simulations. Journal of Computational and Graphical Statistics 7(4), 434-455.

[2] Cebula, Richard and Edgard Feige. 2011. America's Underground Economy: Measuring the Size, Growth and Determinants of Income Tax Evasion in the U.S. Munich Personal RePEc Archive 29672.

[3] Hotchkiss, Julie and Myriam Quispe-Agnoli. 2008. The labor market experience and impact of undocumented workers. Working paper, Federal Reserve Bank of Atlanta.

[4] Justiniano, Alejandro and Bruce Preston. 2010. Monetary policy and uncertainty in an empirical small open-economy model. Journal of Applied Econometrics 25: 93-128. 
Table A1. Model with capital: prior and posterior distributions of estimated parameters.

\begin{tabular}{|c|c|c|c|c|c|c|c|c|}
\hline \multirow[b]{2}{*}{ Description } & \multicolumn{4}{|c|}{ Prior distribution } & \multicolumn{4}{|c|}{ Posterior distribution } \\
\hline & Name & Density & Mean & Std Dev & Mode & Mean & $10 \%$ & $90 \%$ \\
\hline K Adjust Cost & $\phi^{k}$ & Gamma & 0.5 & 0.3 & 0.0540 & 0.0703 & 0.0355 & 0.1021 \\
\hline Elast Subst K & $\sigma$ & Gamma & 0.52 & 0.15 & 1.0078 & 1.0018 & 0.9460 & 1.0626 \\
\hline Weight leisure & $a_{n}$ & Gamma & 2.78 & 0.2 & 2.4418 & 2.4689 & 2.1634 & 2.7901 \\
\hline Elast. Intert. Subst. & $\gamma$ & Gamma & 2 & 0.3 & 1.7170 & 1.9336 & 1.3325 & 2.4539 \\
\hline Elast. Labor Supply & $\gamma_{n}$ & Gamma & 1.33 & 0.3 & 0.5675 & 0.6058 & 0.4694 & 0.7305 \\
\hline Ice Melting (H) & $\tau$ & Gamma & 1.40 & 0.15 & 1.2982 & 1.3636 & 1.0988 & 1.6114 \\
\hline Ice Melting (F) & $\tau^{*}$ & Gamma & 1.40 & 0.15 & 1.8028 & 1.7581 & 1.5521 & 1.9466 \\
\hline Tech. shock $(\mathrm{H})$ & $\rho_{z}$ & Beta & 0.5 & 0.2 & 0.4769 & 0.4929 & 0.3974 & 0.5828 \\
\hline Tech. shock (F) & $\rho_{z^{*}}$ & Beta & 0.5 & 0.2 & 0.3080 & 0.3401 & 0.0741 & 0.5851 \\
\hline Trade cost shock & $\rho_{\tau}$ & Beta & 0.5 & 0.2 & 0.9912 & 0.9858 & 0.9743 & 0.9982 \\
\hline Demand shock $(\mathrm{H})$ & $\rho_{b}$ & Beta & 0.5 & 0.2 & 0.3349 & 0.4015 & 0.1601 & 0.6301 \\
\hline Demand shock (F) & $\rho_{b^{*}}$ & Beta & 0.5 & 0.2 & 0.9480 & 0.9472 & 0.9278 & 0.9745 \\
\hline IST shock $(\mathrm{H})$ & $\rho_{v x}$ & Beta & 0.5 & 0.2 & 0.8843 & 0.8775 & 0.8422 & 0.9154 \\
\hline IST shock $(\mathrm{F})$ & $\rho_{v x}^{*}$ & Beta & 0.5 & 0.2 & 0.9462 & 0.7777 & 0.5472 & 0.9990 \\
\hline Tech. shock $(\mathrm{H})$ & $\sigma_{z}$ & Inv gamma & 0.01 & $2^{*}$ & 0.0139 & 0.0141 & 0.0121 & 0.0161 \\
\hline Tech. shock (F) & $\sigma_{z^{*}}$ & Inv gamma & 0.01 & $2^{*}$ & 0.0026 & 0.0029 & 0.0019 & 0.0037 \\
\hline Trade cost shock & $\sigma_{\tau}$ & Inv gamma & 0.01 & $2^{*}$ & 0.0138 & 0.0139 & 0.0114 & 0.0165 \\
\hline Demand shock & $\sigma_{b}$ & Inv gamma & 0.01 & $2^{*}$ & 0.0206 & 0.0217 & 0.0162 & 0.0264 \\
\hline IST shock $(\mathrm{H})$ & $\sigma_{v x}$ & Inv gamma & 0.01 & $2^{*}$ & 0.0122 & 0.0144 & 0.0096 & 0.0185 \\
\hline IST shock (F) & $\sigma_{v x}$ & Inv gamma & 0.01 & $2^{*}$ & 0.0027 & 0.0030 & 0.0017 & 0.0041 \\
\hline Global tech. shock & $\sigma_{x}$ & Inv gamma & 0.01 & $2^{*}$ & 0.0209 & 0.0214 & 0.0185 & 0.0242 \\
\hline
\end{tabular}


Table A2: Baseline model without capital-Alternative specifications-

\begin{tabular}{|c|c|c|c|c|c|c|c|c|c|c|}
\hline \multirow[b]{2}{*}{ Description } & \multicolumn{4}{|c|}{ Prior distribution } & \multicolumn{6}{|c|}{ Posterior distribution } \\
\hline & Name & Density & Mean & Std Dev & Mode & Mean & Mode & Mean & Mode & Mean \\
\hline Weight leisure & $a_{n}$ & Gamma & 2.78 & 0.2 & 2.7282 & 2.5692 & 2.7701 & 2.6575 & 2.8286 & 2.7725 \\
\hline Elast. Intert. Subst. & $\gamma$ & Gamma & 2 & 0.3 & 0.6367 & 0.6860 & 1.8266 & 0.9434 & 0.7985 & 0.8407 \\
\hline Elast. Labor Supply & $\gamma_{n}$ & Gamma & 1.33 & 0.3 & 1.1829 & 1.2274 & 1.4524 & 1.5619 & 1.0590 & 1.2071 \\
\hline Ice Melting (H) & $\tau$ & Gamma & 1.40 & 0.15 & 1.2549 & 1.2504 & 1.3745 & 1.3663 & 1.2388 & 1.2383 \\
\hline Ice Melting (F) & $\tau^{*}$ & Gamma & 1.40 & 0.15 & 1.4107 & 1.4136 & 1.4379 & 1.4085 & 1.4532 & 1.4876 \\
\hline Tech. shock $(\mathrm{H})$ & $\rho_{z}$ & Beta & 0.5 & 0.2 & 0.9949 & 0.9927 & 0.7798 & 0.9898 & 0.9894 & 0.9890 \\
\hline Tech. shock (F) & $\rho_{z^{*}}$ & Beta & 0.5 & 0.2 & 0.8330 & 0.8017 & 0.5358 & 0.6630 & 0.7409 & 0.7250 \\
\hline Trade cost shock $(\mathrm{H})$ & $\rho_{\tau}$ & Beta & 0.5 & 0.2 & 0.9947 & 0.9919 & 0.9878 & 0.9713 & 0.9858 & 0.9841 \\
\hline Demand shock $(\mathrm{H})$ & $\rho_{b}$ & Beta & 0.5 & 0.2 & 0.9352 & 0.9316 & 0.4101 & 0.9276 & 0.9139 & 0.9232 \\
\hline Demand shock (F) & $\rho_{b^{*}}$ & Beta & 0.5 & 0.2 & 0.9583 & 0.9519 & 0.5161 & 0.8674 & 0.8832 & 0.8686 \\
\hline Tech. shock (H) & $\sigma_{z}$ & Inv gamma & 0.01 & $2^{*}$ & 0.0410 & 0.0424 & 0.0642 & 0.0485 & 0.0415 & 0.0443 \\
\hline Tech. shock (F) & $\sigma_{z^{*}}$ & Inv gamma & 0.01 & $2^{*}$ & 0.0320 & 0.0320 & 0.0389 & 0.0366 & 0.0285 & 0.0314 \\
\hline Trade cost shock (H) & $\sigma_{\tau}$ & Inv gamma & 0.01 & $2^{*}$ & 0.0055 & 0.0061 & 0.0150 & 0.0087 & 0.0181 & 0.0190 \\
\hline Trade cost shock (F) & $\sigma_{\tau^{*}}$ & Inv gamma & 0.01 & $2^{*}$ & - & - & - & - & 0.0039 & 0.0047 \\
\hline Demand shock $(\mathrm{H})$ & $\sigma_{b}$ & Inv gamma & 0.01 & $2^{*}$ & 0.0103 & 0.0110 & 0.0735 & 0.0161 & 0.0118 & 0.0138 \\
\hline Demand shock $(\mathrm{F})$ & $\sigma_{b^{*}}$ & Inv gamma & 0.01 & $2^{*}$ & - & - & 0.0047 & 0.0065 & 0.0046 & 0.0053 \\
\hline Global tech. shock & $\sigma_{x}$ & Inv gamma & 0.01 & $2^{*}$ & 0.0256 & 0.0261 & 0.0301 & 0.0263 & 0.0266 & 0.0265 \\
\hline$\Delta \log (\hat{L})$ & & & & & & & -32.87 & & -132.61 & \\
\hline
\end{tabular}


Figure TA1. Forecast error variance decompositions.

Q1

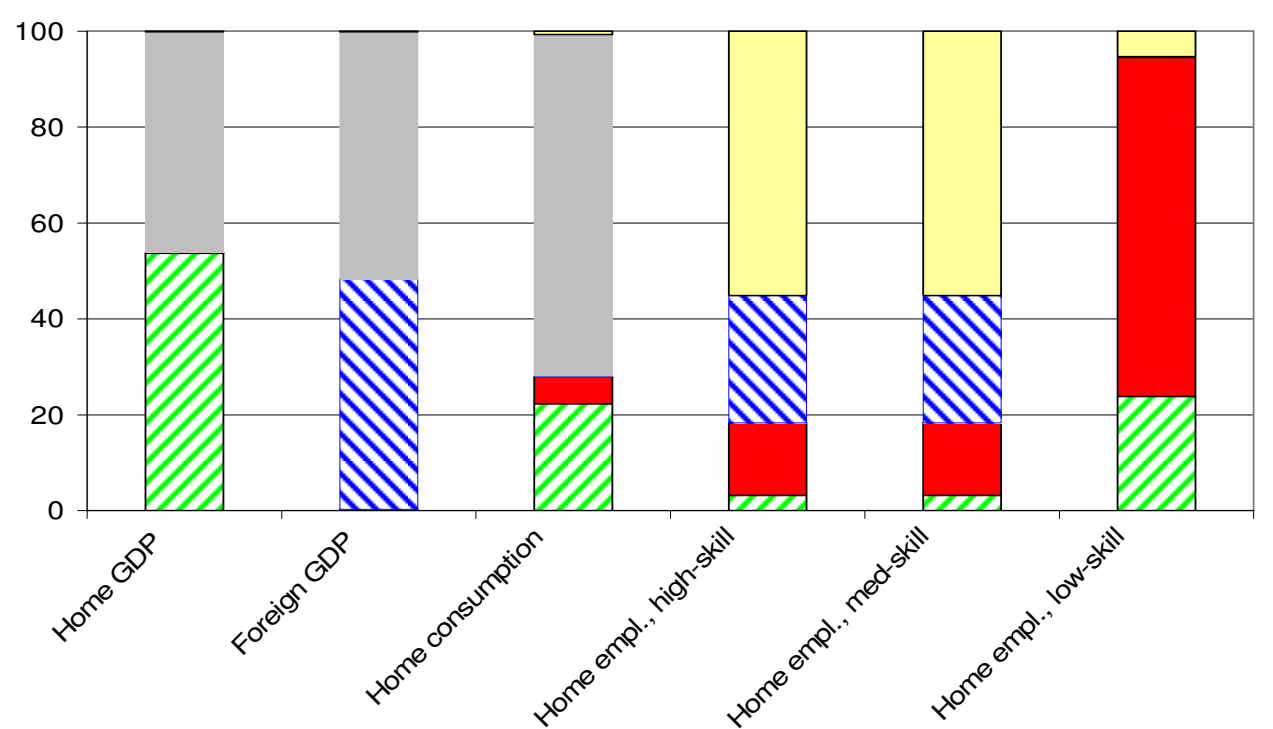

$\square$ Tech (Home) $\quad \square$ Dem (Home) $\mathbf{\Delta}$ Tech (Foreign) $\quad$ Tech (Global) $\square$ Trade cost Q16

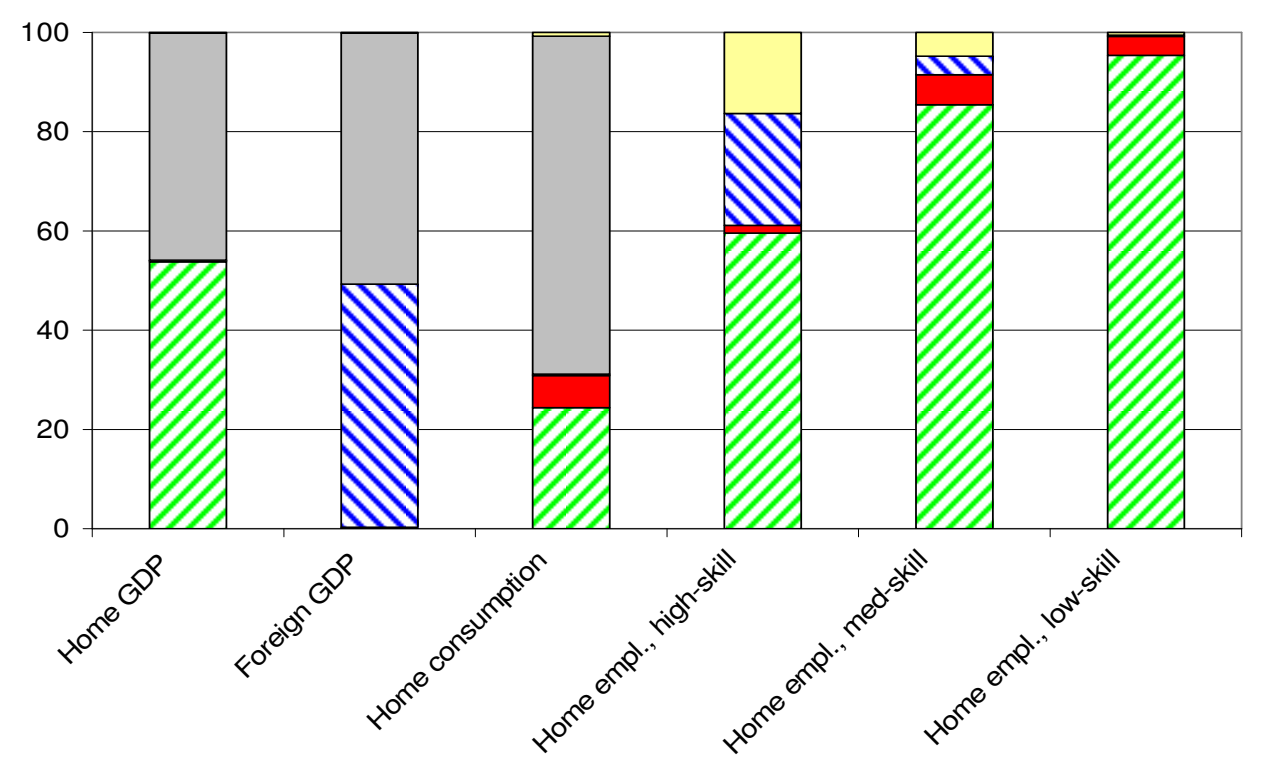

$\square$ Tech (Home) $\quad \square$ Dem (Home) $\boldsymbol{\nabla}$ Tech (Foreign) $\square$ Tech (Global) $\square$ Trade cost

\section{Q4}

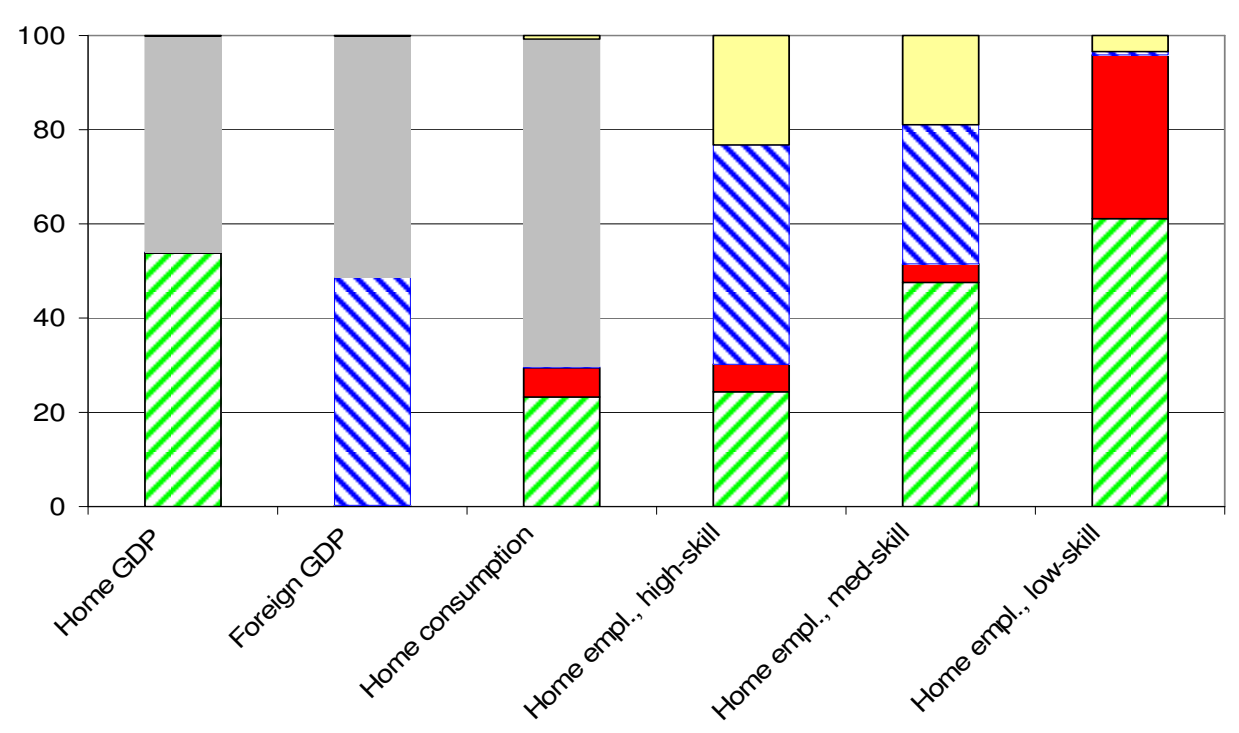

$\square$ Tech (Home) $\square$ Dem (Home) $\quad$ Tech (Foreign) $\square$ Tech (Global) $\square$ Trade cost Q40

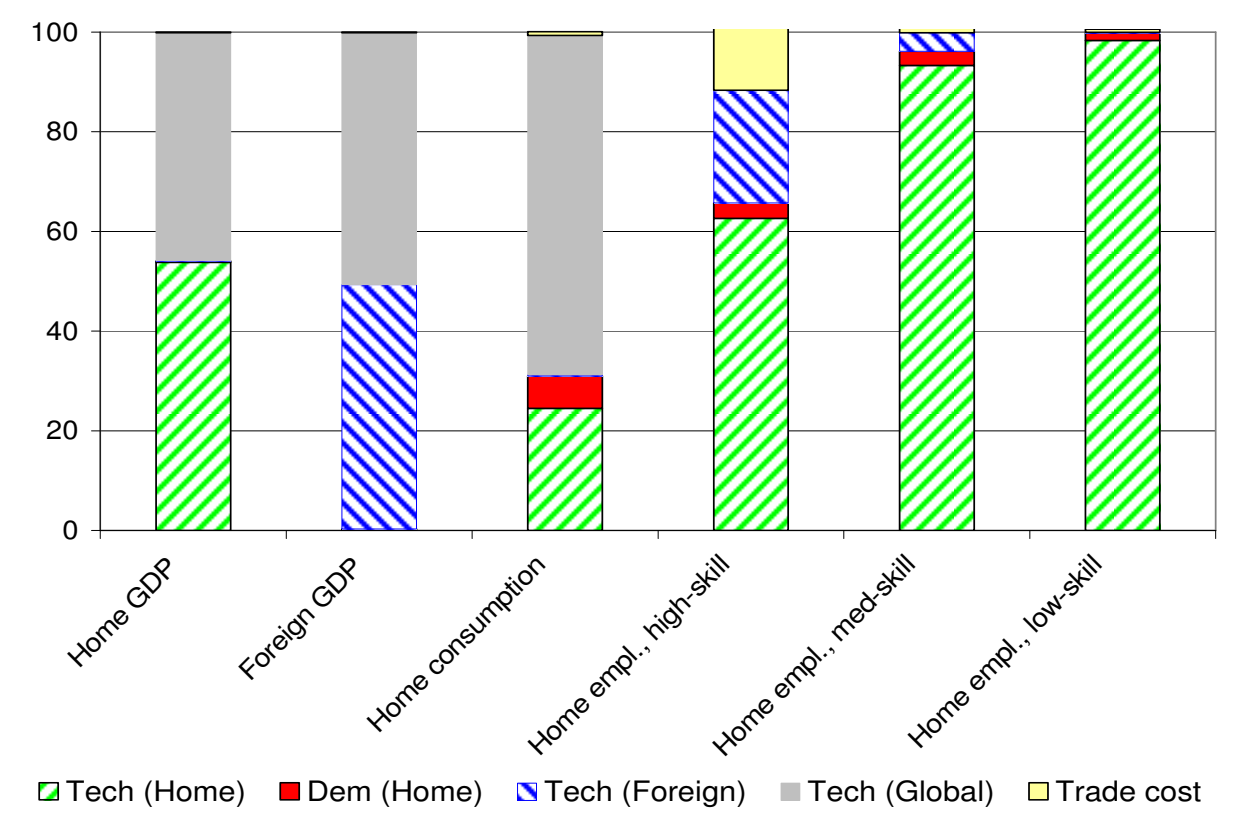

Note: Forecast variance decomposition at the posterior mode, at forecast horizons: Q1, Q4, Q16 and Q40. 
Figure TA2- Prior and posterior distributions
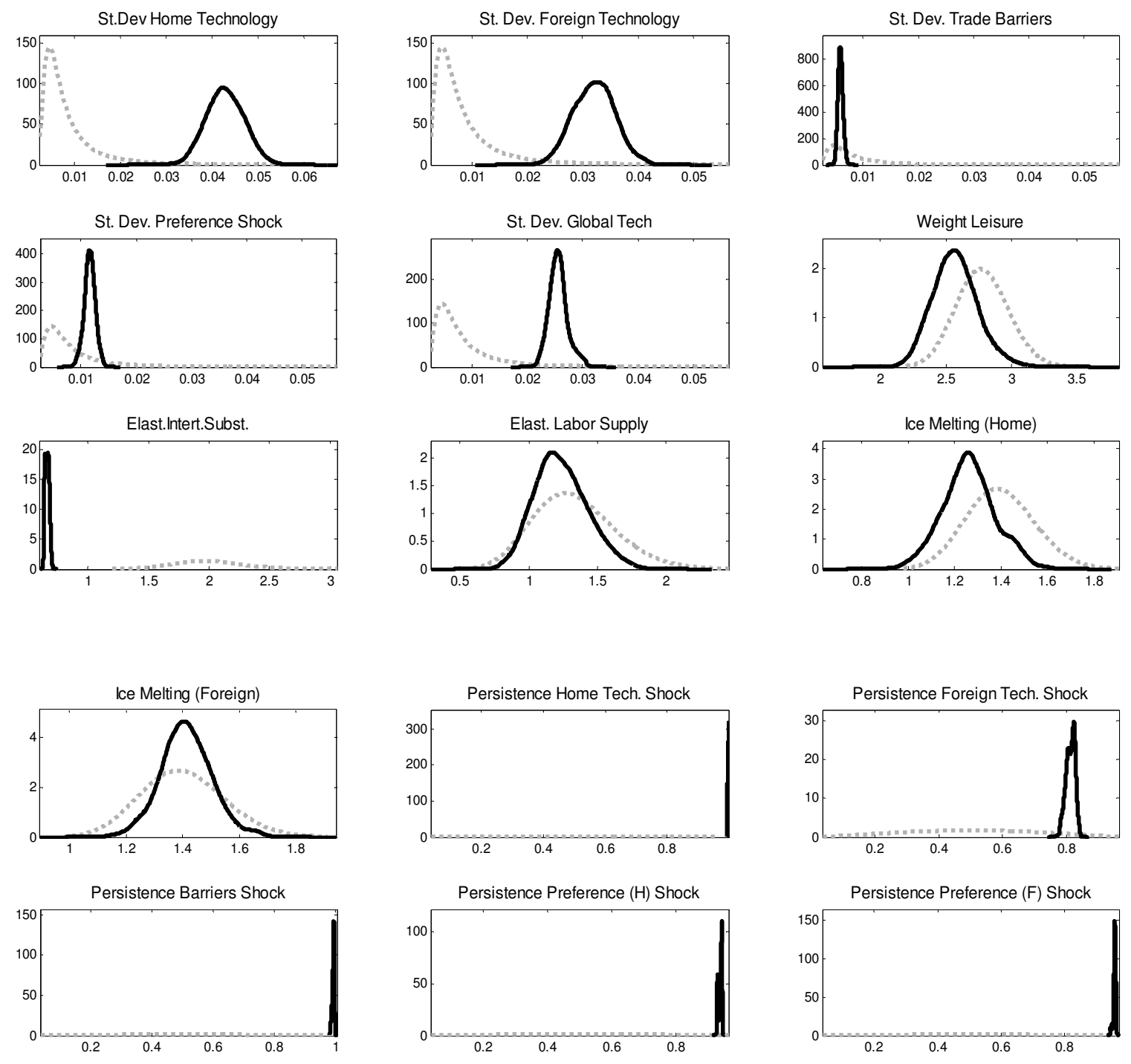

Note: Benchmark Model. Results based on 100,000 draws of the Metropolis algorithm. Gray line: prior. Black line: posterior. 
Figure TA3- Markov Chain Monte Carlo (MCMC) multivariate convergence diagnostics
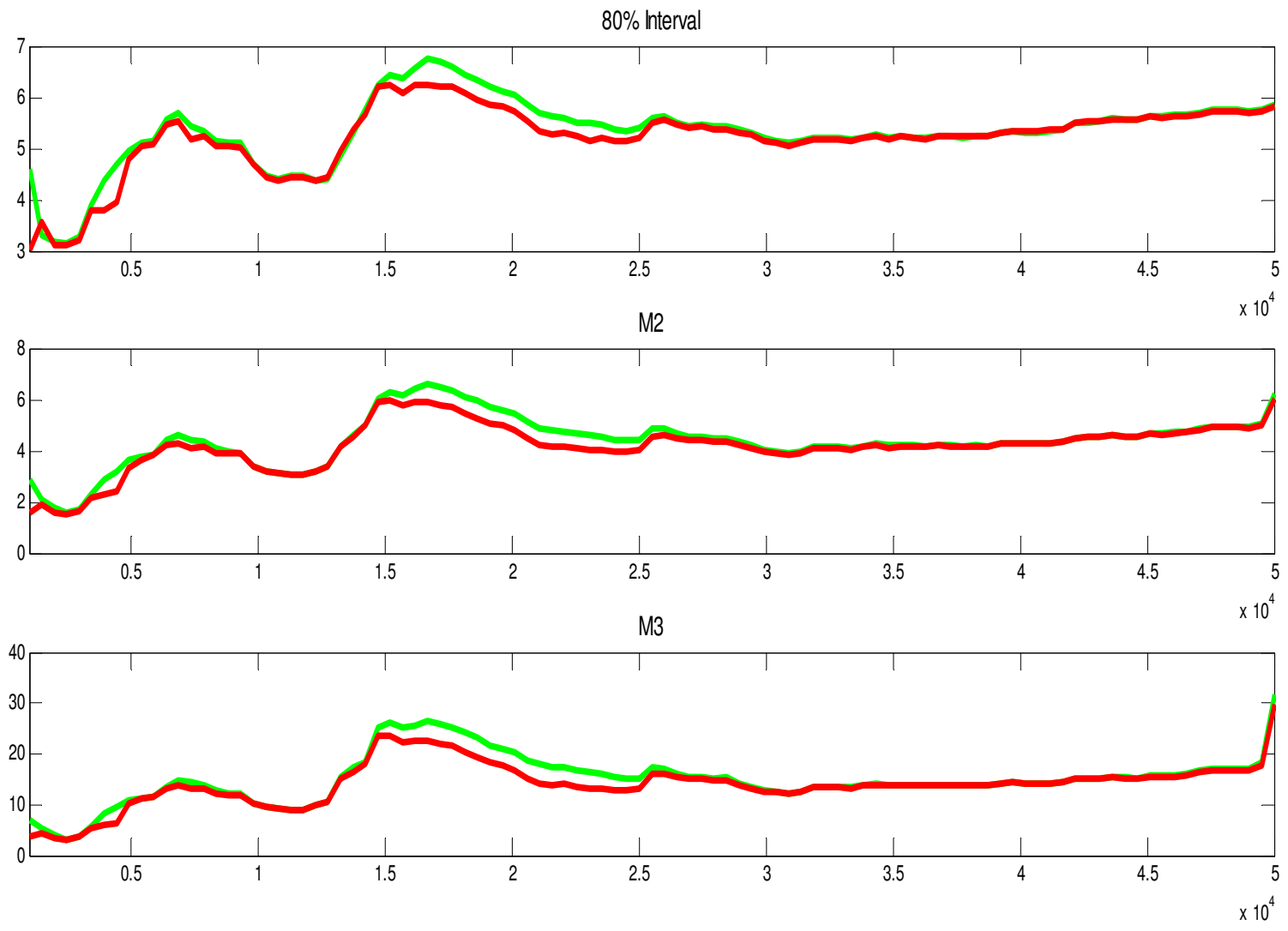

Note: Multivariate convergence diagnostics (Brooks and Gelman, 1988). The eighty percent interval, second and third moments are displayed. 